\title{
The regulation of IL-10 production by immune cells
}

\section{Margarida Saraiva* and Anne O’Garra}

Abstract | Interleukin-10 (IL-10), a cytokine with anti-inflammatory properties, has a central role in infection by limiting the immune response to pathogens and thereby preventing damage to the host. Recently, an increasing interest in how IL10 expression is regulated in different immune cells has revealed some of the molecular mechanisms involved at the levels of signal transduction, epigenetics, transcription factor binding and gene activation. Understanding the specific molecular events that regulate the production of IL-10 will help to answer the remaining questions that are important for the design of new strategies of immune intervention.

*Microbiology and Infection Research Domain, Life and Health Sciences Research Institute (ICVS), School of Health Sciences, University of Minho, Campus de Gualtar, 4710-057 Braga, Portugal. ${ }^{\ddagger}$ Division of Immunoregulation Medical Research Council National Institute for Medical Research, The Ridgeway, Mill Hill, London NW7 1AA UK.

Correspondence to $A . O^{\prime} \mathrm{C}$ e-mail: aogarra@nimr.mrc.ac.uk doi:10.1038/nri2711 Published online 15 February 2010
The immune response has evolved to protect the host from a wide range of potentially pathogenic microorganisms, but parallel mechanisms to control overexuberant immune responses and prevent reactivity to self are required to limit host damage. Interleukin-10 (IL-10) is an anti-inflammatory cytokine with a crucial role in preventing inflammatory and autoimmune pathologies ${ }^{1-3}$. IL-10-deficient mice ${ }^{4}$ develop inflammatory bowel disease following colonization of the gut with particular microorganisms ${ }^{5}$ (BOX 1) and show other exaggerated inflammatory responses to microbial challenge. Although the absence of IL-10 leads to better clearance of some pathogens with no enhanced immunopathology $y^{6,7}$, during other infections the absence of IL-10 can be accompanied by an immunopathology that is detrimental to the host but does not necessarily affect the pathogen load ${ }^{3,8-11}$. This suggests that an absence of IL-10 is not always compensated by other regulatory mechanisms and thus that there is a non-redundant role for IL-10 in limiting inflammatory responses in vivo.

To inhibit inflammatory pathologies, IL-10 functions at different stages of an immune response and possibly at different anatomical locations. IL-10 was initially described as a T helper $2\left(\mathrm{~T}_{\mathrm{H}} 2\right)$-type cytokine ${ }^{12}$, but further evidence suggested that the production of IL-10 was associated with tolerant or regulatory $\mathrm{T}\left(\mathrm{T}_{\mathrm{Reg}}\right)$ cell responses ${ }^{3,13,14}$. It is now known that the expression of IL-10 is not specific to $\mathrm{T}_{\mathrm{H}} 2$ cells or $\mathrm{T}_{\mathrm{Reg}}$ cells but instead that it is a much more broadly expressed cytokine (FIG. 1). IL-10 is expressed by many cells of the adaptive immune system, including $\mathrm{T}_{\mathrm{H}} 1, \mathrm{~T}_{\mathrm{H}} 2$ and $\mathrm{T}_{\mathrm{H}} 17$ cell subsets, $\mathrm{T}_{\text {Reg }}$ cells, $\mathrm{CD} 8^{+} \mathrm{T}$ cells and $\mathrm{B}$ cells (reviewed in
REFS 3,10,11,14-16). It is also expressed by cells of the innate immune system, including dendritic cells (DCs), macrophages, mast cells, natural killer (NK) cells, eosinophils and neutrophils ${ }^{3}$ (FIG. 1). Thus, IL-10 production seems to be associated with many immune cells, affirming its crucial role as a feedback regulator of diverse immune responses, not only $\mathrm{T}_{\mathrm{H}} 1$ cell responses ${ }^{10,11}$ but also $\mathrm{T}_{\mathrm{H}} 2$ cell responses to schistosome parasites ${ }^{17}$, Aspergillus spp. ${ }^{18}$ and allergens ${ }^{19}$ (reviewed in REF. 1).

Much is known about the function of IL-10. For example, the induction of the anti-inflammatory response mediated through the IL-10 receptor (IL-10R) and activation of signal transducer and activator of transcription 3 (STAT3) is reviewed in REFS 3,20. By acting on DCs and macrophages, IL-10 inhibits the development of $\mathrm{T}_{\mathrm{H}}$ 1-type responses (reviewed in REF. 3) but also leads to the suppression of $\mathrm{T}_{\mathrm{H}} 2$ cell and allergic responses (reviewed in REF. 1). In addition to an autocrine inhibitory effect of IL-10 on macrophages and DCs, and because IL-10 can be produced by $\mathrm{T}_{\mathrm{H}} 1$, $\mathrm{T}_{\mathrm{H}} 2$ and $\mathrm{T}_{\mathrm{H}} 17$ cells, an additional feedback loop exists to limit the innate effector functions of macrophages and DCs and their subsequent activation of T cells. However, IL-10 enhances the differentiation of IL-10secreting $\mathrm{T}_{\mathrm{Reg}}$ cells, thus providing a positive regulatory loop for its induction ${ }^{21}$ (reviewed in REFS 1,14). In some situations, IL-10 also activates mast cells and enhances the functions of $\mathrm{CD}^{+} \mathrm{T}$ cells, NK cells and $B$ cells (reviewed in REFS 2,3), although these effects have yet to be tested in infection models.

So, IL-10 is a cytokine with important effects on the development of an immune response. An understanding of how IL10 expression is regulated in different innate 


\section{Box 1 | IL-10 expression and gut homeostasis}

The intestine is continuously exposed to bacterial flora, dietary antigens and potential pathogens. To prevent chronic intestinal inflammation, various regulatory lymphocyte populations keep the immune response in check. These populations use several regulatory mechanisms, the best characterized of which involves interleukin-10 (IL-10) and transforming growth factor- $\beta$ (TGF $\beta)^{15,155}$. IL-10- or IL-10 receptor-deficient mice do not develop severe autoimmune disorders but develop colitis in the presence of microorganisms ${ }^{4,156}$. Many studies unequivocally identify $\mathrm{CD}^{+} \mathrm{T}$ cell-derived IL-10 as a key mediator of intestinal immune homeostasis ${ }^{157-161}$. Coeliac disease and inflammatory bowel disease (IBD) are the most common causes of non-infectious intestinal inflammation in humans, with recent reports identifying IL10 as a susceptibility locus for the development of IBD ${ }^{162}$. Polymorphisms in nucleotide-binding oligomerization domain 2 (NOD2) have also been associated with IBD in humans ${ }^{163}$, which is interesting considering that NOD2 has been associated with IL-10 production ${ }^{41}$. IL-10 seems to function not directly on T cells, but instead on myeloid cell populations in a similar manner to that observed in the immune response to pathogens ${ }^{3}$. In vivo IL-10 production by forkhead box P3 $\left(\mathrm{FOXP}^{+}\right)$regulatory $\mathrm{T}\left(\mathrm{T}_{\mathrm{Reg}}\right)$ cells and FOXP3- regulatory $\mathrm{T}$ cells in the gut seems to be mediated by TGF $\beta$, independently of endogenous IL-10 (REF. 97). This IL-10 independence is in contrast to that reported in vitro for human IL-10-producing regulatory $T$ cells ${ }^{14}$. Retinoic acid was identified as a cofactor for TGF $\beta$ in the induction of FOXP3 ${ }^{+} \mathrm{T}_{\text {Reg }}$ cells ${ }^{164-166}$, although retinoic acid itself downregulates the expression of IL-10 by inducible FOXP3- regulatory T cells ${ }^{92}$. Although the exact mechanisms of IL-10 induction in the intestine remain elusive, the protective role of intestinal $\mathrm{T}_{\text {Reg }}$ cells mostly depends on their expression of IL-10, suggesting that local IL-10 expression might be a therapy for IBD².

\section{Chromatin}

Composed of nucleosomes,

this is the basic repeating unit of eukaryotic genomes.

Nucleosomes consist of 146 base pairs of DNA wound around an octamer of histone proteins.

Plasmacytoid DC

A DC that lacks myeloid markers such as $\mathrm{CD} 11 \mathrm{c}$ and CD33 but expresses high levels of HLA-DR and CD 123. These cells produce high levels of type I interferons in response to viral infection. and adaptive immune cells is therefore of importance for the development of immune intervention strategies in various pathologies. Several layers of regulation of IL-10 expression exist, and this is a main focus of this Review. First, regulation of IL-10 production involves changes in the chromatin structure at the IL10 locus. A second layer of regulation involves the enhancement or silencing of IL10 transcription and is controlled by specific transcription factors activated by discrete signal-transduction pathways. In addition, posttranscriptional mechanisms exist. Many of the molecular events leading to IL10 expression are common to various IL-10-producing immune cells. However, there are also cell-specific signals and molecular mechanisms that allow IL-10 production by particular immune cells and not by others.

In this Review, we discuss our current understanding of the regulation of IL10 expression at the molecular level in different cell types, from signal transduction pathways to epigenetic regulation and the activation of specific transcription factors involved in IL-10 production. Throughout, we highlight the common and distinct mechanisms of IL-10 regulation that exist in different IL-10-producing immune cells.

\section{IL-10 production by immune cells}

Induction by pathogen-derived products. Pathogen activation of DCs and macrophages involves the recognition of pathogen-derived products by pattern recognition receptors (PRRs), which triggers the expression of cytokines and other factors ${ }^{22}$. Both macrophages $^{23-27}$ and $\mathrm{DCs}^{26,28-33}$ can express IL-10 in vitro following activation of specific PRRs (FIG. 2a). In addition, $\mathrm{DCs}^{31,34}$, macrophages ${ }^{35}$ and neutrophils ${ }^{36}$ have been reported to express IL-10 in vivo.
It has been suggested that Toll-like receptor 2 (TLR2) agonists are specialized in inducing IL-10 expression by antigen-presenting cells (APCs) ${ }^{29,30,37,38}$. For example, TLR2 signalling is crucial for the induction of IL-10 production by macrophages (M. Teixeira-Coelho, J. Carmona, A. G. Castro and M.S., unpublished observations) or by $\mathrm{DCs}^{39}$ stimulated with Mycobacterium tuberculosis or with lipopeptides and the LcrV antigen of Yersinia pestis ${ }^{40}$. IL-10 production by macrophages following pneumoccocal cell wall stimulation mainly depends on TLR2; however, in this case a role for nucleotide-binding oligomerization domain 2 (NOD2) signalling, independent of TLR2, has also been described $^{41}$. Significant amounts of IL-10 are also produced by macrophages and myeloid DCs following stimulation with TLR4 and TLR9 ligands ${ }^{26}$. Of note, IL-10 production following TLR3 stimulation was only observed in macrophages ${ }^{26}$. Interestingly, activation of macrophages through TLRs results in high levels of IL-10 production, whereas myeloid DCs only produce intermediate amounts and plasmacytoid DCs (pDCs) do not produce detectable levels of IL-10 (REF. 26) (FIG. 1). In addition, IL-10 can be induced by TLR-independent stimuli, such as the C-type lectins DC-specific ICAM3grabbing non-integrin (DC-SIGN; also known as CLEC4M) ${ }^{33}$ and dectin 1 (also known as CLEC7A) ${ }^{32}$ (FIG. 2a). Ligation of CD40 enhances IL-10 production by TLR-stimulated ${ }^{28}$ or dectin 1-stimulated $\mathrm{DCs}^{32}$ and ligation of Fc receptors (FcRs) enhances IL-10 production by TLR-stimulated macrophages ${ }^{25}$.

Signalling pathways for innate IL-10 production. Following TLR ligation, signalling cascades are activated through Toll/IL-1 receptor (TIR)-domain-containing adaptor molecules, such as myeloid differentiation primary-response protein 88 (MYD88) and TIR-domaincontaining adaptor protein inducing IFN $\beta$ (TRIF; also known as TICAM1), leading to the production of IL-10 and pro-inflammatory cytokines ${ }^{26,30,42}$. TLR signalling through MYD88 leads to the activation of mitogenactivated protein kinases (MAPKs) and nuclear factor- $\kappa B$ $(\mathrm{NF}-\kappa \mathrm{B})^{43}$ (FIG. 2a).

Additional signals that are required for IL-10 production by macrophages have also been reported. Of note, optimal lipopolysaccharide (LPS)-induced IL-10 production by macrophages requires both the activation of the TRIF- and MYD88-dependent pathways ${ }^{26,27}$ and the production of and signalling by type I interferons (IFNs) ${ }^{27}$. This secondary induction of IL-10 by type I IFNs has important implications for the use of type I IFNs as potential anti-inflammatory drugs. Moreover, this study is in line with the observation that TNFR-associated factor 3 (TRAF3), an important component of the type I IFN production pathway, is also involved in LPS-induced upregulation of IL-10 expression $^{42}$.

The MAPK cascade is composed of three major groups of kinases: extracellular signal-regulated kinases (ERKs) (comprising ERK1 (also known as MAPK3) and ERK2 (also known as MAPK1), which are collectively referred to here as ERK); JUN N-terminal kinases 


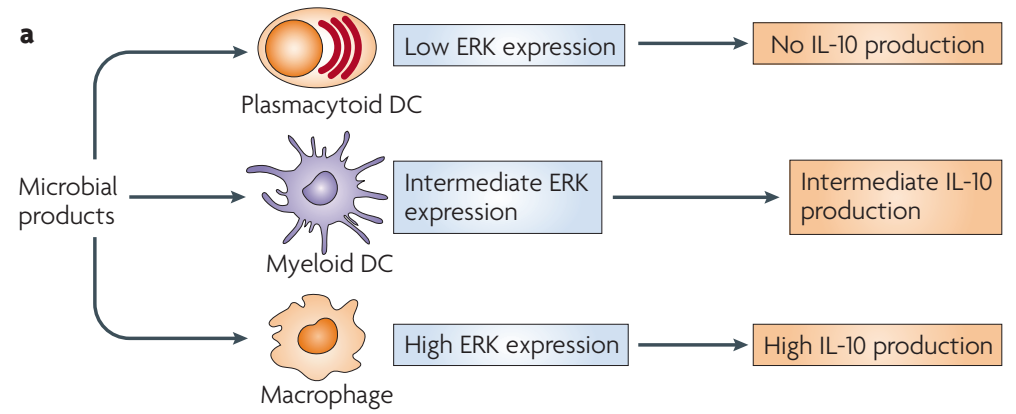

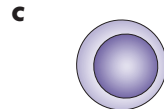

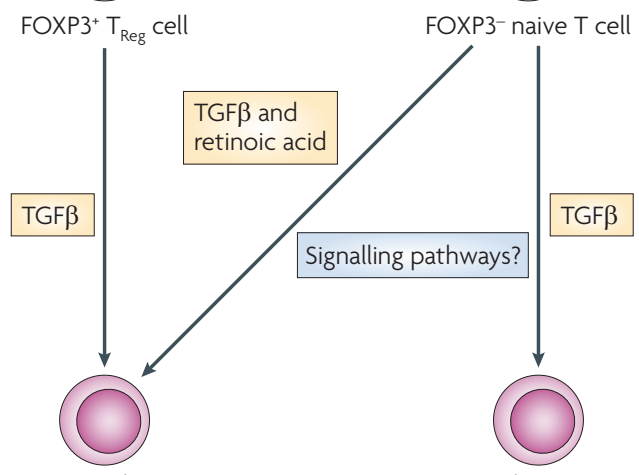

IL-10-producing $\mathrm{FOXP3}^{+} \mathrm{T}_{\text {Reg }}$ cell

$\mathrm{T}_{\mathrm{H}} 17$ cell

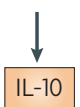

TGF $\beta$, LL-6, IL-21 and/or IL-27

\section{STAT3}

ERK

IL-10
IL-10-producing

FOXP3- regulatory $T$ cell

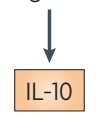

Figure 1 | Interleukin-10 expression in the immune system. a | Interleukin-10 (IL-10) is expressed by macrophages and myeloid dendritic cells (DCs), but not by plasmacytoid DCs, in response to microbial products. The extracellular signal-regulated kinase 1 (ERK1) and ERK2 (which are collectively referred to here as ERK) pathway is one of the signalling cascades that is activated in these cells that results in IL-10 expression. For other immune cells, such as B cells, mast cells and eosinophils, the exact signalling pathways that lead to IL-10 production remain elusive. $\mathbf{b} \mid \ln T$ helper $\left(\mathrm{T}_{H}\right)$ cells, the expression of IL-10 is accompanied by the expression of the signature cytokines for each subset, with the exception of regulatory $T\left(T_{\text {Reo }}\right)$ cells, which normally lose the capacity to express other cytokines. Although the differentiation of $T_{H}$ cells from naive $\mathrm{CD}^{+}{ }^{+} \mathrm{T}$ cells requires $\mathrm{T}$ cell receptor triggering and the activation of distinct signal transducer and activator of transcription (STAT) pathways, activation of the ERK pathway is a common requirement for IL-10 expression by these cells. High doses of antigen presented by DCs to naive T cells or IL-12 favours the development of $\mathrm{T}_{H} 1$ cells, which produce interferon- $\gamma$ (IFN $\gamma$ ). IL-10-producing $T_{H} 1$ cells require high antigen dose and IL-12 and STAT4 signalling for the expression of maximum levels of IL-10 following re-stimulation. In $\mathrm{T}_{\mathrm{H}} 2$ cells, IL-4 and STAT6 signalling pathways are required for IL-10 expression. Induction of IL-10-producing $T_{H} 17$ cells is not well understood, but transforming growth factor- $\beta$ (TGF $\beta$ ), IL-6, IL-21 and/or IL-27 and STAT3 signalling are likely to be involved. c | TGF $\beta$ can induce the production of IL-10 by forkhead box P3 (FOXP3) ${ }^{+} T_{\text {Reg }}$ cells and this cytokine can also promote the development of IL-10-producing FOXP3- regulatory $T$ cells from naive $T$ cells. Conversely, FOXP3 ${ }^{+} \mathrm{IL}-10$-producing $\mathrm{T}_{\text {Reg }}$ cells can differentiate from naive T cells in vitro in the presence of TGF $\beta$ and retinoic acid.

(JNKs) (comprising JNK1 (also known as MAPK8) and JNK2 (also known as MAPK9)); and p38 (REF. 44). Following TLR stimulation, activation of ERK modulates IL-10 expression ${ }^{30,45-47}$, and in the presence of chemical inhibitors of ERK ${ }^{30,45,47}$ or in ERK-deficient cells ${ }^{46}$ IL-10 production by TLR-activated DCs is decreased. Furthermore, the differences in IL-10 production by macrophages, myeloid DCs and pDCs have been shown to correlate with the strength of ERK activation in each of these cell types ${ }^{47}$. Following TLR stimulation, ERK is most highly activated in macrophages, with lower activation of ERK in myeloid DCs and the lowest amount of activated ERK in $\mathrm{pDCs}^{47}$ (FIG. 1).
Further studies using cells deficient for tumour progression locus 2 (TPL2) or NF- $\kappa \mathrm{B} 1$ (also known as p105) support the role of ERK in the induction of IL-10. TPL2 is an upstream activator of ERK and, following TLR stimulation, TPL2 dissociates from the TPL2NF- $\kappa \mathrm{B} 1$ complex and activates ERK. In the absence of NF- $\kappa B 1$, TPL2 is rapidly degraded in the cell and, as a consequence, ERK activation by TPL2 is compromised $^{48}$. In TPL2-deficient macrophages and myeloid DCs the amounts of TLR-induced IL-10 were lower than in wild-type cells owing to the absence of ERK activation $^{47}$. Similarly, NF- $\kappa B 1$-deficient macrophages have lower levels of IL-10 expression than control cells 
a

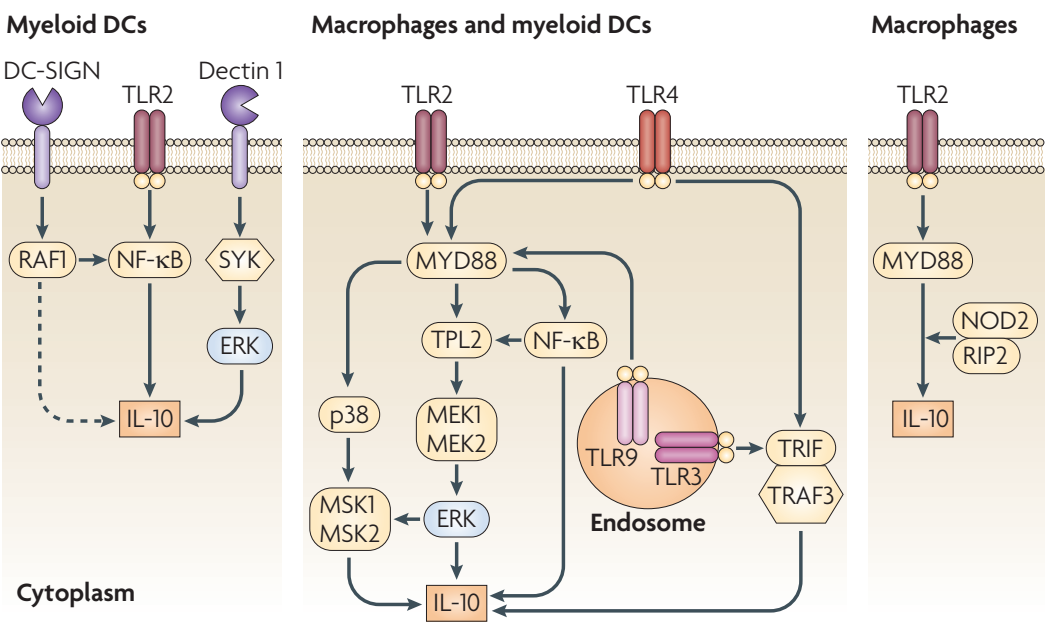

b

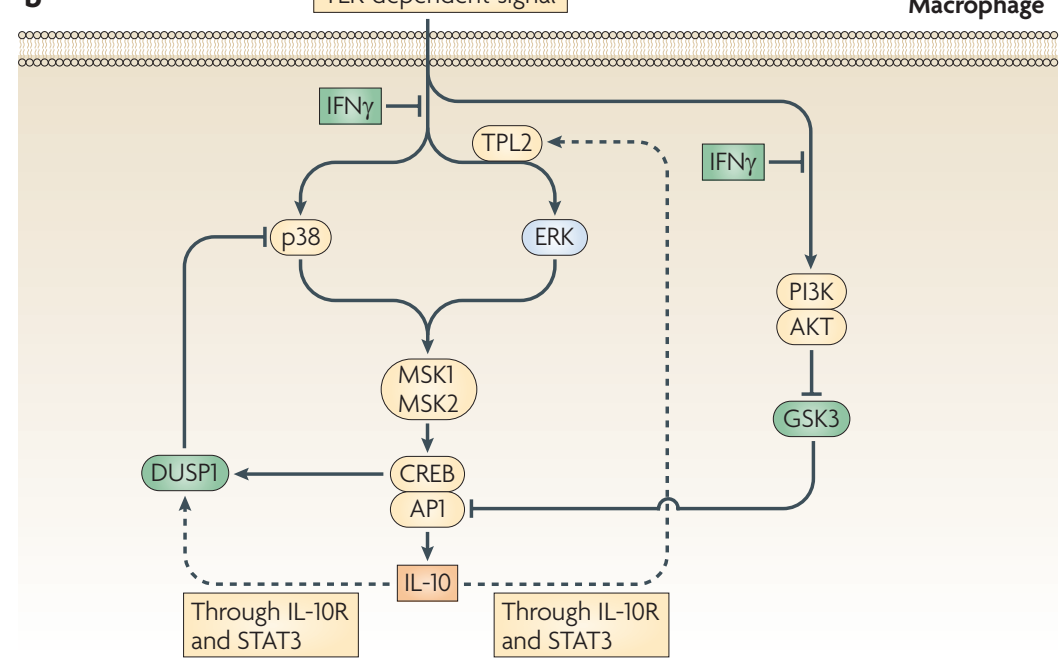

Figure 2 | Signals that induce interleukin-10 expression by cells of the innate immune response. a |The expression of interleukin-10 (IL-10) can be induced by Toll-like receptor (TLR) or non-TLR signalling in macrophages and myeloid dendritic cells (DCs). Activation of TLRs and their adaptor molecules — myeloid differentiation primary-response protein 88 (MYD88) and TIR-domain-containing adaptor protein inducing IFN $\beta$ (TRIF) — results in the activation of the extracellular signal-regulated kinase 1 (ERK1) and ERK2 (which are collectively referred to here as ERK), p38 and nuclear factor- $\kappa B(N F-\kappa B)$ pathways. Activation of these pathways results in the induction of IL-10 expression, in addition to pro-inflammatory cytokines. In myeloid DCs, non-TLR signals through DC-specific ICAM3-grabbing non-integrin (DC-SIGN) and RAF1 can augment TLR2-induced IL-10 production. Furthermore, activation of dectin 1 and the signalling molecules spleen tyrosine kinase (SYK) and ERK results in IL-10 production. In macrophages, a role for nucleotide-binding oligomerization domain 2 (NOD2) signalling in IL-10 induction, in crosstalk with TLR2, has been described. b| Positive and negative feedback loops for IL-10 regulation in macrophages. The $\mathrm{p} 38$ and ERK pathways leading to IL-10 expression by macrophages are tightly controlled by interferon- $\gamma$ (IFN $\gamma)$ and IL-10 itself. IL-10 feeds back to induce the expression of dual-specificity protein phosphatase 1 (DUSP1), which negatively regulates $\mathrm{p} 38$ phosphorylation and thus limits IL-10 production. IL-10 can also positively feed back to upregulate tumour progression locus 2 (TPL2) expression, thus providing a positive amplification loop for its own production. In addition, IFN $\gamma$ can also interfere with the phosphoinositide 3-kinase (PI3K)-AKT pathway, releasing glycogen synthase kinase 3 (GSK3). As GSK3 normally blocks IL-10 expression by acting on the transcription factors CAMP response element-binding protein (CREB) and activator protein 1 (AP1), IL-10 production is inhibited by IFN $\gamma$ through its effects on PI3K. IL-10R, IL-10 receptor; MEK, MAPK/ERK1 kinase; MSK, mitogen- and stress-activated protein kinase; RIP2, receptor-interacting protein 2; STAT3, signal transducer and activator of transcription 3; TRAF3, TNFR-associated factor 3. following TLR activation ${ }^{49}$. IL-10 expression was only partially restored following rescue of ERK activation in these cells ${ }^{49}$, indicating that NF- $\kappa \mathrm{B}$-mediated regulation of IL-10 production involves both ERK-dependent and ERK-independent mechanisms, as had been suggested by previous studies ${ }^{50,51}$. Furthermore, pathogen triggering of DC-SIGN in human DCs resulted in the activation of RAF1, leading to acetylation of the NF- $\kappa \mathrm{B}$ p 65 subunit and to prolonged and increased IL10 transcription ${ }^{52}$. This effect was only observed after TLR-dependent NF- $\kappa B$ activation, suggesting that activation of DC-SIGN can modulate TLR-induced IL-10 production ${ }^{52}$.

The regulation of IL-10 production in response to dectin 1 ligation depends on spleen tyrosine kinase $(\underline{\mathrm{SYK}})^{32}$. SYK is recruited to phosphorylated dectin 1 (REF. 53) and initiates a signalling cascade that induces IL-2 and IL-10 production $^{32}$. IL-10 production downstream of dectin 1 also requires signalling through the ERK pathway, despite being independent of TLR activation $^{54}$ (FIG. 2a). Furthermore, IL-10 production by FcR ligation in the presence of TLR signals in macrophages can also lead to ERK activation ${ }^{55}$. Therefore, ERK activation is common to several signalling pathways upstream of IL10 in macrophages and DCs.

IL-10 expression can also be compromised by inhibition of p38 signalling in LPS- or CpG-activated macrophages ${ }^{45,56-58}$, primary $\mathrm{DCs}^{59}$ and human peripheral blood monocytes ${ }^{60}$. Primary cells lacking the p38 regulator dual-specificity protein phosphatase 1 (DUSP1) have prolonged p38 activation and increased levels of IL-10 expression following TLR stimulation ${ }^{61-63}$. This could be reversed by chemically inhibiting p38 signalling ${ }^{61,62}$.

Interestingly, abrogation of either ERK or p38 activation leads to a reduction, but not abrogation, of IL-10 expression, which suggests that these two pathways might cooperate in TLR-induced IL-10 production. Supporting this hypothesis, inhibition of both the ERK and p38 pathways in LPS- or CpG-stimulated macrophages leads to an almost complete abrogation of IL-10 production (A.O'G., unpublished observations). Furthermore, deficiency of mitogen- and stress-activated protein kinase 1 (MSK1; also known as RPS6Ka5) and MSK2 (also known as RPS6Ka4), which are activated downstream of the p38 and ERK pathways, correlated with a loss of IL-10 expression by LPS-stimulated macrophages ${ }^{64}$.

The production of IL-10 by macrophages and DCs is also regulated by the activation of certain inhibitory pathways. ERK- and p38-dependent IL-10 production is inhibited by IFN $\gamma^{38}$ (FIG. 2b). In addition to directly blocking TLR-induced MAPK activation, IFN $\gamma$ induces the release of glycogen synthase kinase 3 (GSK3) by antagonizing phosphoinositide 3-kinase (PI3K)-AKT activation. This leads to inhibition of TLR-induced IL-10 production by suppressing the binding of activator protein 1 (AP1) to the $I l 10$ promoter $^{38}$. Another negative feedback loop controlling IL- 10 production by macrophages is mediated by IL-10 itself. IL-10 induces the expression of DUSP1, which negatively regulates p 38 phosphorylation and thus limits IL-10 production ${ }^{65}$. By contrast, IL-10 positively feeds back to upregulate Tpl2 expression ${ }^{66}$, thus providing a positive amplification 
loop for its own production. IL-10 was also described to induce its own transcription in human monocytes in a STAT3-dependent manner ${ }^{67}$, which may result from its upregulation of TPL2 and thus ERK activation ${ }^{66}$. However, the mechanisms dictating the balance between IL-10-mediated negative and positive feedback loops are currently not clear. Furthermore, the inhibition of IL-10 production by NK cell- or T cell-derived IFN $\gamma$ in vivo will also influence these loops.

Various pathogen-derived products induce IL10 expression by macrophages and DCs through the activation of signalling cascades that, although common to various stimuli and different cells, have distinct thresholds of activation depending on the cell type, which reflect the distinct amounts of IL-10 produced by these cells.

IL-10 production by $T_{H}$ cells. IL-10 production was first described in $\mathrm{T}_{\mathrm{H}} 2$ cells $\mathrm{s}^{12,68}$, where its expression accompanies that of the $\mathrm{T}_{\mathrm{H}} 2$-type cytokines IL-4, IL-5 and IL-13. $\mathrm{T}_{\mathrm{H}} 1$ cells can also be induced to produce IL-10, but, in contrast to $\mathrm{T}_{\mathrm{H}} 2$ cells, only under certain conditions ${ }^{10,11,15,69-76}$ (FIG. 1). Furthermore, $\mathrm{T}_{\mathrm{H}} 17$ cells have recently been shown to produce IL-10 (REFS 72, 77-79). The fact that $\mathrm{T}_{\mathrm{H}} 1, \mathrm{~T}_{\mathrm{H}} 2$ and $\mathrm{T}_{\mathrm{H}} 17$ cells are dependent on DC- and macrophage-derived factors that are downregulated by IL-10, but these subsets can all be induced to produce IL-10, is indicative of a negative feedback loop that ensures that effector $\mathrm{T}$ cell responses do not result in immunopathology. It is of interest to note that IL-9producing $\mathrm{T}_{\mathrm{H}}$ cells, which have recently been suggested to be a unique $\mathrm{T}_{\mathrm{H}}$ cell subset ( $\mathrm{T}_{\mathrm{H}} 9$ cells), also express IL-10 (REF. 80).

Molecular signals for IL-10 induction in $T_{H}$ cells. IL-10-inducing signalling cascades have been studied less thoroughly in $\mathrm{T}_{\mathrm{H}}$ cells than in macrophages and DCs. IL-10-producing $\mathrm{T}_{\mathrm{H}} 1$ cells have been described in infectious diseases, human $\mathrm{CD}^{+} \mathrm{T}$ cell clones and mouse $\mathrm{CD}^{+} \mathrm{T}$ cells. $\mathrm{T}_{\mathrm{H}} 1$ cells that produce both IFN $\gamma$ and IL-10 can be generated by inducing T cells to proliferate with high levels of antigen-specific or polyclonal stimulation in the presence of IL-12 (REFS 10,11,69,70) (FIG. 1). However, until recently the signals that determine whether $\mathrm{T}_{\mathrm{H}} 1$ cells produce IL-10 were not known. Strong $\mathrm{T}$ cell receptor (TCR) triggering (high antigen dose) $)^{71}$ and endogenous IL-12 have now been shown to be essential for the differentiation of IL-10-producing $\mathrm{T}_{\mathrm{H}} 1$ cells, as well as for maximal expression of IL-10 following restimulation of these cells ${ }^{72}$. IL-10 induction in $\mathrm{T}_{\mathrm{H}} 1$ cells is STAT4 and ERK dependent ${ }^{72}$ (FIG. 1). Notch signalling can also induce IL-10 expression by $\mathrm{T}_{\mathrm{H}} 1$ cells, a process that requires STAT4 (REF. 81). In $\mathrm{T}_{\mathrm{H}} 2$ cells, IL-10 production seems to be regulated by the main $\mathrm{T}_{\mathrm{H}} 2$ type-associated signalling pathways and transcription factors: IL-4, STAT6 and GATA binding protein 3 (GATA3) ${ }^{82-84}$. IL-10 expression by $\mathrm{T}_{\mathrm{H}} 17$ cells seems to occur in a STAT3- and, in some cases, STAT1-dependent manner ${ }^{79,85}$ (FIG. 1). Thus, to induce IL-10 expression, $\mathrm{T}_{\mathrm{H}} 1, \mathrm{~T}_{\mathrm{H}} 2$ and $\mathrm{T}_{\mathrm{H}} 17$ cells require the same signals needed for each $\mathrm{T}_{\mathrm{H}}$ cell differentiation programme. However, IL-10 production by all these subsets requires ERK activation ${ }^{72}$, indicating that a common molecular mechanism exists for IL-10 production by $\mathrm{T}_{\mathrm{H}}$ cells. Chemical inhibition of the $\mathrm{p} 38$ signalling pathway did not compromise the production of IL- 10 by $\mathrm{T}_{\mathrm{H}} 1, \mathrm{~T}_{\mathrm{H}} 2$ or $\mathrm{T}_{\mathrm{H}} 17$ cells $^{72}$, suggesting that in $\mathrm{T}_{\mathrm{H}}$ cells the role of ERK is dominant over that of $\mathrm{p} 38$. This observation is in contrast to a joint role for ERK and p38 in IL-10 induction in macrophages and DCs.

IL-21 can enhance IL-10 expression by $\mathrm{CD} 4^{+} \mathrm{T}$ cells in the context of different stimuli ${ }^{86}$, and IL-27 enhances IL-10 expression by $\mathrm{T}_{\mathrm{H}} 1, \mathrm{~T}_{\mathrm{H}} 2$ and $\mathrm{T}_{\mathrm{H}} 17$ cells $^{78,79,85,87,88}$. By contrast, IL-27 attenuates TLR-induced IL10 expression by human monocytes ${ }^{89}$. Of interest, it has recently been shown that both IL-21 and IL-27 induce ERK activation ${ }^{90,91}$, but it is currently not clear whether this explains the ability of these cytokines to upregulate IL-10 production. Also, both IL-21 and IL-27, in addition to ERK, activate STAT3, which seems to be involved in IL-27-mediated IL-10 upregulation by T cells ${ }^{79}$.

Undoubtedly, all T cell subsets can produce IL-10, as well as their hallmark cytokines, following TCR triggering, but this depends on the environmental context and strength of stimulus ${ }^{10,11,69-73,92-94}$.

IL-10 and regulatory $T$ cells. $\mathrm{T}_{\mathrm{Reg}}$ cells, which are characterized by their specific expression of the transcription factor forkhead box P3 (FOXP3), do not express IL-10 following stimulation directly after ex vivo isolation $^{95,96}$, unless isolated from the gut ${ }^{97}$ (BOX 1). Although FOXP $^{+} \mathrm{T}_{\text {Reg }}$ cells inhibit naive $\mathrm{T}$ cell proliferation in vitro independently of IL-10, in some cases, $\mathrm{T}_{\text {Reg }}$ cells mediate their regulatory function in vivo through IL-10 (reviewed in REFS 1,14,16,98-100). Therefore, $\mathrm{T}_{\mathrm{Reg}}$ cells must receive signals in vivo to induce the expression of this suppressive cytokine. Both IL-2 and IL- 4 have been shown to induce IL-10 production after culture of $\mathrm{T}_{\text {Reg }}$ cells in vitro ${ }^{101,102}$. However, in these studies, the $\mathrm{T}_{\text {Reg }}$ cell population analysed might have contained some effector T cells and therefore the source of IL-10 cannot be confirmed. So far the signals that induce IL-10 expression by FOXP $3^{+} \mathrm{T}_{\text {Reg }}$ cells remain elusive, although transforming growth factor $\beta$ (TGF $\beta$ ) has been shown to be required in $v i v o^{97}$ (FIG. 1).

Several populations of antigen-driven FOXP3 IL-10-producing T cells with regulatory activity that are distinct from naturally occurring $\mathrm{T}_{\mathrm{Reg}}$ cells have been described (reviewed in REFS 1,2,13,14). These cells produce IL-10, but not IL-2, IL- 4 or IFN $\gamma$, and can be generated in vitro using various stimuli, such as cytokine cocktails (TGF $\beta$, IL-10 and IFNa) or immunosuppressive drugs (vitamin D3 and dexamethasone) $)^{1,2,13,14,21}$, or in vivo by repeated stimulation with soluble antigen ${ }^{71,103}$. Additional signals for IL-10 expression by these FOXP3regulatory $\mathrm{T}$ cells include co-stimulation through CD2 or CD46 and stimulation with type I IFNs or with immature DCs (reviewed in REFS 1,14,104). Signals delivered through inducible T cell co-stimulator (ICOS) have also been suggested to induce IL-10 expression by FOXP3- regulatory T cells ${ }^{105,106}$; a similar effect has been observed in $\mathrm{T}_{\mathrm{H}} 2$ cells ${ }^{107,108}$, suggesting that, although it is involved in the induction of IL-10, ICOS is not a cell type-specific inducer of IL-10. 
DNasel hypersensitive sites

Sites of nuclease sensitivity in the nuclei on exposure of cells to limiting concentrations of DNasel. The digested regions of DNA correspond to sites of open DNA, which might be factor-binding sites or areas of altered nucleosome conformation

Chromatin remodelling Alterations that are induced in chromatin by enzymes that modify the extent of acetylation, methylation or other covalent modifications of histones.

Acetylation

A post-translational modification of chromatin components, particularly histones. It correlates with actively transcribed chromatin.
It will be of interest to determine whether IL-10producing FOXP3- regulatory $\mathrm{T}$ cells differentiate directly from naive $T$ cells or are derived from $T_{H} 1, T_{H} 2, T_{H} 9$ or $\mathrm{T}_{\mathrm{H}} 17$ cells that have lost expression of their effector $\mathrm{T}$ cell cytokines but have maintained IL-10 expression. It is possible that FOXP3- regulatory $\mathrm{T}$ cells that only make IL-10 have originally differentiated along a $\mathrm{T}_{\mathrm{H}} 1$ cell pathway through repeated high-level antigenic stimulation, which results in IL-10 production and ultimately in the downregulation of $\mathrm{T}_{\mathrm{H}} 1$ cell production of IFN $\gamma$ by feedback inhibition of IL-12 production by DCs and macrophages ${ }^{71}$.

Additional cell types that produce IL-10. In addition to macrophages, DCs and CD4 ${ }^{+} \mathrm{T}$ cells, other cells of the immune system are also known to express IL-10. $\mathrm{CD}^{+} \mathrm{T}$ cells express IL-10 following TCR activation or interaction with CD40 ligand expressed by activated $\mathrm{pDCs}^{109-111}$, and this IL-10 production can be enhanced by IL-21 (REF. 86). Stimulation of B cells with autoantigens, TLR4 and TLR9 ligands or vitamin D3 also leads to IL-10 production ${ }^{112-117}$. Finally, mast cells can express IL-10 following TLR4 activation or during skin allergic or damage responses ${ }^{1,118,119}$. Recently, neutrophils were reported to produce IL-10 in response to TLR and C-type lectin co-activation through MYD88 and SYK, respectively ${ }^{36}$. These IL-10-producing neutrophils were shown to be recruited to the lung during mycobacterial infections and to regulate local immune inflammatory responses ${ }^{36}$. It is currently not clear whether the molecular mechanisms required for the induction of IL-10 by these cells are regulated by the common factors that regulate IL-10 production by $\mathrm{T}_{\mathrm{H}}$ cells, macrophages and DCs.

\section{Box 2 | Epigenetic control of IL10 expression}

Several studies suggest that the expression of interleukin-10 (IL-10) is regulated by changes in the structure of the chromatin at the IL10 locus ${ }^{51,133-135}$ (FIG. 3). Various DNasel hypersensitive sites (HSSs) were found in the mouse Il10 locus, most of which are common to IL-10-producing T cells, macrophages and dendritic cells (DCs). However, a macrophage-specific regulatory element (HSS-4.5), which is absent in T cells, was also found ${ }^{51}$. Although chromatin remodelling seems to be one of the initial events leading to IL10 expression, additional signals are required to allow high rates of IL10 transcription. Epigenetic imprinting of the ll10 locus in mice, as measured by histone acetylation, was observed in high-IL-10-producing T helper $2\left(\mathrm{~T}_{\mathrm{H}} 2 \text { cells }\right)^{84}$ and macrophages ${ }^{51}$ but not in low-IL-10-producing $\mathrm{T}_{H} 1$ cells ${ }^{84}$, despite the open conformation of the IL10 locus observed for all these cell types. In macrophages, the histones at the Il10 locus were also reported to be hyperphosphorylated ${ }^{55,167}$. Furthermore, by interacting with the distal segment of the IL10 promoter, histone deacetylase 11 negatively regulated the expression of this cytokine in human and mouse antigen-presenting cells ${ }^{168}$.

Several studies have identified GATA binding protein 3 (GATA3) as a possible initiator of chromatin remodelling and histone acetylation of the ll10 locus in mice ${ }^{83,133}$. However, as GATA3 is only expressed by $\mathrm{T}_{\mathrm{H}} 2$ cells and not in other IL-10-producing $T_{H}$ cells, macrophages or DCs, other mechanisms must operate in these cells to induce chromatin remodelling at the ll10 locus. A clue may come from the finding that, in macrophages, remodelling of the ll10 locus occurs following TLR stimulation ${ }^{51}$ or $\mathrm{Fc}$ receptor binding in an extracellular signal-regulated kinase (ERK)-dependent manner ${ }^{55}$.

Overall, analysis of the chromatin conformation at the IL10 locus may help to explain the different levels of IL10 expression and the different factors involved in this expression by different cell types, although many questions still remain unanswered.
Understanding the molecular pathways leading to IL-10 production by different immune cells might provide valuable information on possible targets for IL-10 manipulation. This will be useful in the design of intervention strategies to modulate IL-10 production and ultimately the immune response.

\section{Transcription factors that regulate IL-10}

Activating the IL10 promoter. The structure of the human and mouse IL10 promoters is similar and both contain a TATA box and a CCAAT box (CCAGT in mice). The human and mouse IL10 promoters have a high level of homology, particularly around certain putative binding sites for transcription factors. However, the presence of a conserved putative binding site in a gene promoter does not guarantee transcription factor binding.

In addition to epigenetic control (BOX 2), the expression of IL10 depends on transcription factor binding. The transcription factors specific protein $1(\mathrm{SP} 1)^{120}, \mathrm{SP} 3$ (REF. 121), CCAAT/enhancer binding protein- $\beta(\mathrm{C} / \mathrm{EBP} \beta)^{122,123}$, IFNregulatory factor 1 (IRF1) and STAT3 (REF. 124) have been proposed to bind to and transactivate IL10 in macrophage and $\mathrm{T}$ cell lines of mouse or human origin (FICS 3, 4). Also, binding of the NF- $\kappa$ B p50 subunit to the IL10 promoter in a human $\mathrm{T}$ cell lymphoma cell line has been described ${ }^{125}$. Moreover, some of these findings depend on the cell type and on the stimulus used. For example, whereas one study indicates that IL10 promoter activity relies on an SP1 site located between positions -636 and -631 relative to the initiation site $^{56}$, another report shows that IL10 promoter activity relies on the C/EBP5 motif positioned between the TATA box and the translation start point ${ }^{122}$. Although both studies were carried out using the human promonocytic cell line THP1, the type of stimulation was different (LPS versus cyclic AMP (cAMP), respectively), which might account for the differences observed.

Studies using mouse primary cells have shown that homodimers of NF- $\kappa \mathrm{B}$ p50 bind to the proximal Il10 promoter, activating $I l 10$ transcription in primary macrophages ${ }^{126}$, and p50-deficient macrophages have an impaired expression of IL-10 following LPS stimulation compared with wild-type macrophages ${ }^{126}$. Furthermore, IL-10 induction in response to double-stranded RNA stimulation and viral infection of mouse macrophages was described to be protein kinase $\mathrm{R}$ (PKR) dependent and to be regulated by binding of NF- $\kappa \mathrm{B}$ to a distinct site in the $I l 10$ promoter ${ }^{127}$. In addition to NF- $\kappa B$, a role for $\mathrm{C} / \mathrm{EBP} \beta$ in $\mathrm{CAMP}$-mediated IL-10 production was confirmed in mouse primary macrophages; nuclear accumulation and DNA binding of C/EBP $\beta$ was involved in IL-10 production in response to adenosine and Escherichia coli infection, and C/EBP $\beta$-deficient macrophages failed to produce IL-10 (REF. 128).

Recently, two cofactors of the homeobox (HOX) family, pre-B-cell leukaemia transcription factor 1 (PBX1) and PBX-regulating protein 1 (PREP1), were implicated in inducing IL-10 expression by mouse macrophages ${ }^{129}$. In this study, the expression of IL-10 was triggered by the interaction of macrophages with apoptotic cells and depended on p38; in human cells, transcription of IL10 cells was mediated by the binding of PBX1 and 


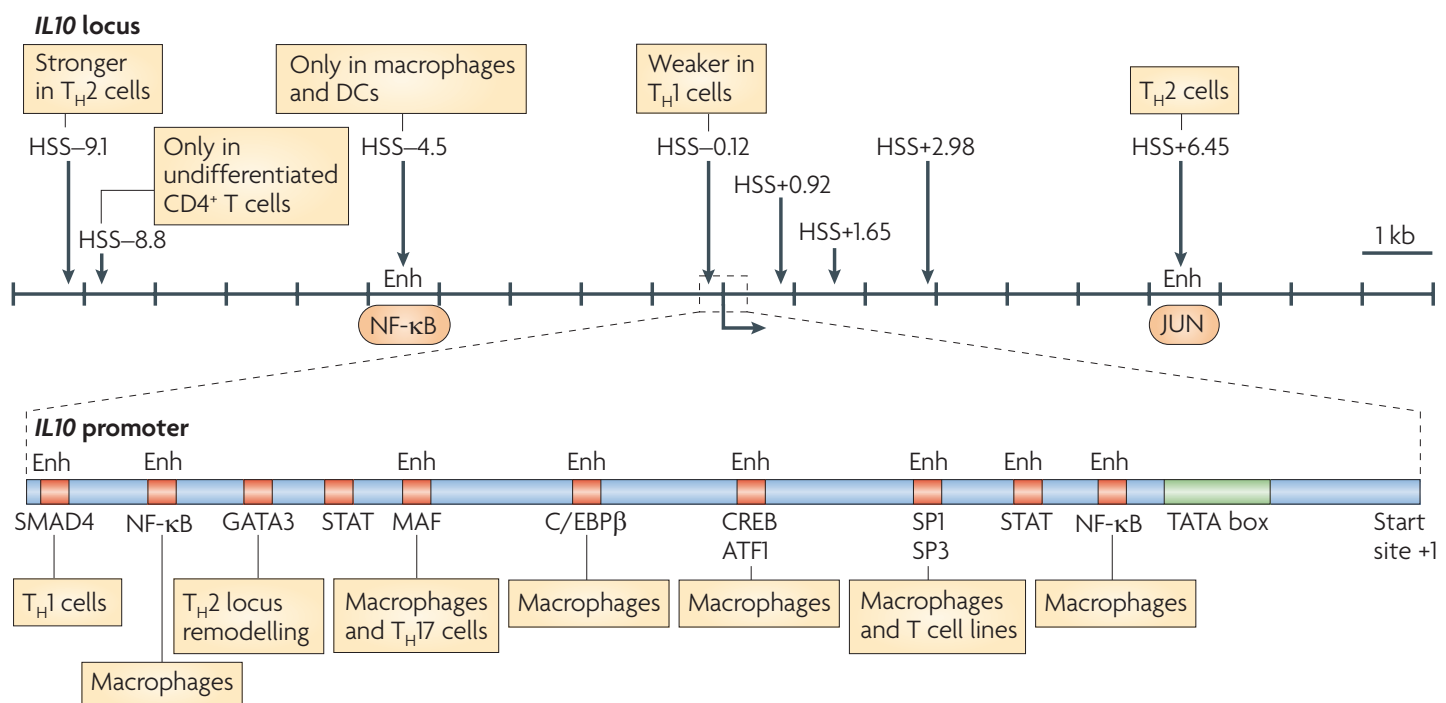

Figure 3 | Molecular regulation of interleukin-10 expression: the interleukin-10 locus and promoter. The mouse interleukin-10 (Il10) locus (top panel) and Il10 promoter (bottom panel) are represented here. Several DNasel hypersensitive sites (HSSs), and their relative position to the $1 / 10$ starting site (+1), are indicated. Most of these HSSs are common to all cells, although some cellular specificity is also observed. Two of these sites (HSS-4.5 and HSS+6.45) have been studied in more detail, and their role in $1 / 10$ regulation has been described. HSS -4.5 contains hyperacetylated histones and binds nuclear factor- $\kappa B$ (NF-kB) in macrophages, whereas HSS +6.45 binds JUN proteins in Thelper 2 ( $\left.\mathrm{T}_{H} 2\right)$ cells. Both HSS-4.5 and HSS+6.45 were shown to enhance the 1110 promoter activity in reporter assays. The biological role for the other HSSs needs to be further clarified. The proximal elements that regulate the expression of IL-10, including the $/ 10$ promoter, have been well studied. Several transcription factors have been shown to bind to the $\| 10$ promoter and to enhance $l l 10$ transcription in various cell types. In $\mathrm{T}_{\mathrm{H}} 2$ cells, GATA binding protein 3 (GATA3) functions as a master regulator for $1 / 10$ expression by binding to sites in the $\| 10$ locus (including to the promoter) and inducing locus remodelling. Also represented are putative signal transducer and activator of transcription (STAT) binding sites in the mouse $l 110$ promoter. ATF1, activating transcription factor 1; C/EBP $\beta$, CCAAT/enhancer binding protein- $\beta$; CREB, cAMP-responsive-element-binding protein; $D C$, dendritic cell; Enh, enhancer; GATA3, GATA binding protein 3; SMAD4, mothers against decapentaplegic homologue 4; SP, specific protein.

PREP1 to the apoptotic cell-response element (ACRE) in the $I L 10$ promoter ${ }^{129}$. The transcription factors cAMPresponsive-element-binding protein (CREB) and activating transcription factor 1 (ATF1) have been shown to be activated by MSKs in LPS-stimulated mouse macrophages and to bind to the Illo promoter, thus suggesting a direct effect of the kinases MSK1 and MSK2 in the regulation of IL-10 induction ${ }^{64}$ (FIG. 2b). There is also evidence for TGF $\beta 1$-induced SMAD4 binding to and activating the $I l 10$ promoter in mouse $\mathrm{T}_{\mathrm{H}} 1$ cells $^{130}$; however, it is worth noting that TGF $\beta 1$ inhibits the development of $\mathrm{T}_{\mathrm{H}} 1$ and $\mathrm{T}_{\mathrm{H}} 2$ cells in vitro and thus their production of IL-10 (REF. 72).

The transcription factor GATA3 was shown to be a master regulator of IL- 10 expression in mouse $\mathrm{T}_{\mathrm{H}} 2$ cells by binding to and initiating changes in the chromatin structure at the Il10 locus ${ }^{83,84}$. Although one of the binding sites for GATA3 is located in the Il10 promoter, GATA3 alone does not transactivate the $I l 10$ promoter ${ }^{83}$. GATA3 may thus be responsible for remodelling the Il10 locus in $\mathrm{T}_{\mathrm{H}} 2$ cells, with other factors being necessary to induce high levels of IL-10 expression in other cell types such as $\mathrm{T}_{\mathrm{H}} 1$ cells that do not express GATA3 (REFS 69,72).

Originally described as a $\mathrm{T}_{\mathrm{H}} 2$ cell-specific factor ${ }^{131}$, the transcription factor MAF has been shown to bind to the $I l 10$ promoter and have a role in the transcriptional regulation of IL-10 in mouse macrophages stimulated with LPS and IL-4, although MAF alone is not sufficient to induce $I l 10$ expression in these cells ${ }^{132}$. Other recent reports have also implicated MAF in the expression of IL-10 by $\mathrm{T}_{\mathrm{H}} 17$ cells, showing binding of this transcription factor to MAF recognition elements in the Il10 promoter $^{85}$, and in the differentiation of IL-10-producing FOXP3 $^{-}$regulatory $\mathrm{T}$ cells ${ }^{88}$. Finally, MAF expression is also detectable in $\mathrm{T}_{\mathrm{H}} 1, \mathrm{~T}_{\mathrm{H}} 2$ and $\mathrm{T}_{\mathrm{H}} 17$ cells, correlating with IL-10 production, and MAF expression depends on ERK activation in $\mathrm{T}_{\mathrm{H}} 1$ and $\mathrm{T}_{\mathrm{H}} 17$ cells, similar to IL-10 expression ${ }^{72}$. Taken together, these reports suggest that MAF may be a universal transcription factor for the regulation of IL-10 production, important in all IL-10-producing cells of both the innate and the adaptive immune systems.

As discussed, various transcription factors have been described to bind to and activate the IL10 promoter (FIGS 3, 4). The activity of one transcription factor or another to regulate IL10 expression seems to depend on the cell type and the type of stimuli. Furthermore, multiple studies suggest that IL-10 is not regulated in a simple and linear manner, which is in accord with its function to keep diverse immune responses in check.

Enhancing IL10 transcription. Following the description of several distal regulatory elements in $I L 10^{51,133-135}$ (FIC. 3), the search for transcription factors with a role in regulating IL10 expression has been expanded to those that bind regions of the locus outside of the promoter region. 


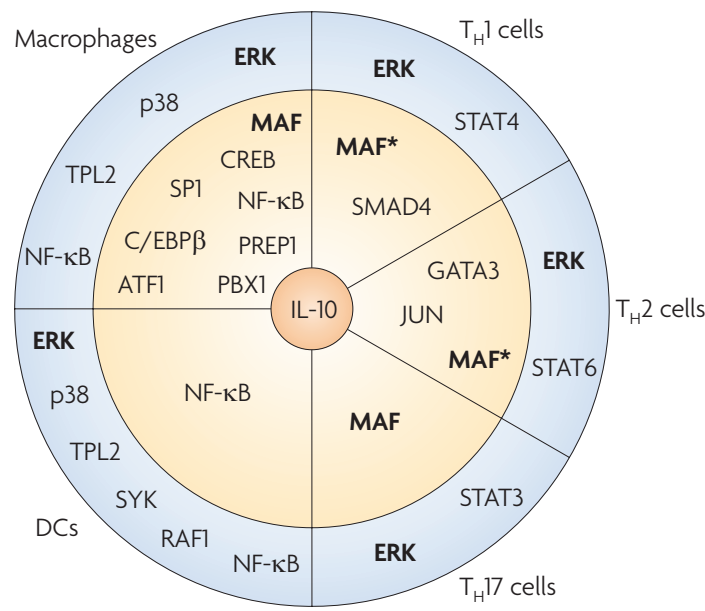

Figure 4 | Transcription factors that control interleukin-10 expression by $\mathrm{CD}^{+} \mathrm{T}$ cells and antigen-presenting cells. Many transcription factors have been found to regulate the expression of interleukin-10 (IL-10) both in antigenpresenting cells and in $\mathrm{CD} 4^{+} \mathrm{T}$ cells. Represented here are the signalling molecules (in the outer circle) and transcription factors (inner circle) involved in IL-10 regulation with a role validated by promoter studies (mutagenesis or chromatin immunoprecipitation) or by studies in genetically modified mice. Part of these studies were carried out in cell lines, although recently the study of IL-10 regulation has involved primary cells. Some of the indicated transcription factors are cell specific and others seem to have a wider role, as discussed in detail in the text. The transcription factors in bold are common to various cell types in regulating $\mathrm{IL}-10$ production. Transcription factors marked with * are those that have not been shown to bind the promoter or the ll10 locus. ATF1, activating transcription factor $1, \mathrm{C} / \mathrm{EBP} \beta, \mathrm{CCAAT} /$ enhancer binding protein- $\beta$; $C R E B$, cAMP-responsive-element-binding protein; DC, dendritic cell; ERK, extracellular signal-regulated kinase; GATA3, GATA binding protein 3; NF- $\mathrm{kB}$, nuclear factor- $\mathrm{KB}$; PBX1, pre-B-cell leukaemia transcription factor 1 ; PREP1, PBX-regulating protein 1; SMAD4, mothers against decapentaplegic homologue 4; SP1, specific protein 1; STAT, signal transducer and activator of transcription; SYK, spleen tyrosine kinase; $T_{H}, T$ helper; TPL2, tumour progression locus 2.

The NF- $\kappa$ B p65 subunit binds to a newly described $\kappa \mathrm{B}$ site located $4.5 \mathrm{~kb}$ upstream of the Il10 start site and has a role in enhancing IL-10 expression by LPSstimulated mouse macrophages ${ }^{51}$ (FIG. 3). This is in keeping with a report that mice deficient for inhibitor of NF- $\kappa B$ kinase 2 (IKK2) show a defect in IL-10 production in LPS-stimulated macrophages ${ }^{50}$. This $\kappa \mathrm{B}$ site is exposed in IL-10-producing LPS-, CpG- or zymosan A-stimulated mouse macrophages and DCs but is absent in $\mathrm{T}$ cells ${ }^{51}$. This suggests that different molecular mechanisms might regulate the expression of $I l 10$ in the innate versus adaptive immune systems and that the production of IL-10 by innate immune cells might be subject to additional regulation, as it is the first checkpoint for the initiation of immune responses and determines the class of the resulting adaptive immune response. Of interest, however, is that ERK signalling is required for optimal IL-10 induction in macrophages, DCs and $\mathrm{T}_{\mathrm{H}}$ cell subsets, which questions whether transcription factors that are required for IL-10 induction in DCs and macrophages may also have a role in inducing IL-10 in T cells. One of the transcription factors implicated in TLR-induced IL-10 expression in mouse macrophages and DCs, by the activation of ERK, is FOS, the expression of which is strongly induced by high levels of ERK activation ${ }^{29,30,47}$.

Studies have suggested there is a role for JUN proteins in regulating $I l 10$ in mouse $\mathrm{T}_{\mathrm{H}} 2$ cells, but not $\mathrm{T}_{\mathrm{H}} 1$ cells, through binding to a regulatory element located $\sim 6.45 \mathrm{~kb}$ downstream of the Il10 start site ${ }^{133,134}$ (FIG. 3). This finding supports our suggestion that alternative mechanisms probably operate to regulate Il10 induction in $\mathrm{T}_{\mathrm{H}} 1$ and $\mathrm{T}_{\mathrm{H}} 2$ cells and possibly in other $\mathrm{T}_{\mathrm{H}}$ cell subsets, although common factors, such as ERK and MAF, are required for Il10 induction in various cell types.

Although there are no data so far to show direct binding of the various STATs to the IL10 locus, an increasing amount of evidence suggests a role for the STAT proteins in regulating the induction of IL-10 expression in both primary macrophages and T cells. In mouse $\mathrm{T}$ cells, the induction of IL-10 by IL-27 seems to depend on both STAT1 (REFS 79,87) and STAT3 (REFS 79,85), and STAT3 is also involved in IL-6induced IL-10 expression ${ }^{79}$. By contrast, a recent study on human monocytes describes an inhibitory role for IL-27 on IL-10 production through STAT1 (REF. 89). In addition, as STAT3 is required for $\mathrm{T}_{\mathrm{H}} 17$ cell differentiation, this transcription factor may have an indirect role in IL-27-mediated induction of IL-10 by $\mathrm{T}_{\mathrm{H}} 17$ cells by modulating $\mathrm{T}_{\mathrm{H}} 17$ cell differentiation. Another study suggests that IL-10 induces its own expression by human monocyte-derived macrophages in an autocrine manner through the activation of STAT3 (REF. 67). In this study, activation of the IL10 promoter depended on the integrity of the STAT3-binding site. Considering the data from human cell lines that show binding of STAT3 to the IL10 promoter $^{124}$, it is possible that the STAT3-dependent effects on IL10 activation in primary cells might be related to promoter transactivation. Finally, STAT4, which is important for the differentiation of IFN $\gamma$ - and IL-10-producing mouse $\mathrm{T}_{\mathrm{H}} 1$ cells $^{72}$, was also reported to have a role in inducing IL-10 expression by mouse NK cells ${ }^{136}$. The molecular mechanisms underlying the participation of other STAT molecules in the control of IL-10 expression require further clarification, particularly as several STAT molecules are required for the differentiation of $\mathrm{T}_{\mathrm{H}}$ cell subsets and thus can modulate the induction of IL-10 in an indirect manner.

The list of transcription factors involved in the regulation of IL10 expression is expanding (FIG. 4), which reflects the degree of precision and complexity that the expression of this cytokine demands. The exact contribution of many of the transcription factors discussed above remains elusive and may in some cases be cell specific, but may also depend on the type of stimulus that triggers IL10 expression or may affect IL10 expression indirectly. With the identification and characterization of distal regulatory regions in the IL10 locus, a role for other transcription factors might also be revealed. 
Silencing IL10 expression. Recent studies have provided evidence for the role of certain transcription factors in silencing Il10 expression. For example, it has been suggested that the transcription factor ETS1 has a role in repressing the production of IL- 10 by mouse $\mathrm{T}_{\mathrm{H}} 1$ cells, as ETS1-deficient $T_{H} 1$ cells show a marked increase in the production of this cytokine ${ }^{137}$. However, it is possible that the effect of ETS1 on IL-10 expression results from diminished $\mathrm{T}_{\mathrm{H}} 1$ cell differentiation, as no interaction of ETS1 with the Il10 locus has been shown. Similarly, an increase in IL-10 expression was observed in mice deficient for the $\mathrm{T}_{\mathrm{H}} 1$ cell-specific transcription factor $\mathrm{T}$-bet (also known as TBX21) that were infected with M. tuberculosis, suggesting that T-bet might have a role in the negative regulation of IL-10 expression by $\mathrm{T}_{\mathrm{H}} 1$ cells $^{138}$. However, as IFN $\gamma$ expression is also lost in the absence of T-bet, this effect on IL- 10 could reflect a blockade of $\mathrm{T}_{\mathrm{H}} 1$ cell differentiation, with the increase in IL-10 expression resulting from other cells. This notion is strongly supported by the observation that IL- 10 production by $\mathrm{T}_{\mathrm{H}} 1$ cells is accompanied by the expression of high levels of IFN $\gamma$ and T-bet ${ }^{69,72}$.

Silencers of IL-10 expression have also been identified in cells of the innate immune response. MHC class II transactivator (CIITA) has been shown to negatively regulate the expression of IL- 10 by mouse DCs and the activity of the Il10 promoter in a mouse macrophage cell line ${ }^{139}$. As mentioned above, it is also possible that STAT1 negatively regulates IL-10 expression in human monocytes ${ }^{89,140}$. However, it is still unclear whether STAT1 directly or indirectly affects the Il10 locus. In addition, isolated peritoneal macrophages from B cell lymphoma 3 (BCL-3)-deficient mice produce increased amounts of IL-10, suggesting that BCL-3 is an inhibitor of IL-10 expression in macrophages; although, again, it is questionable whether this effect is direct or indirect ${ }^{141}$. BCL- 6 has been reported to have a role in inhibiting the production of $\mathrm{T}_{\mathrm{H}} 2$ cell-specific cytokines including IL-10 (REF. 142), and in its absence $\mathrm{T}$ cells activated with strong co-stimulation show a large upregulation of Il4, IllO and Il13 mRNA, whereas overexpression of BCL-6 in wild-type T cells strongly inhibits the production of IL-10 following activation ${ }^{142}$. However, it is unknown whether BCL-6 directly regulates the Il10 locus. In recent reports, BCL- 6 was required for T follicular helper cell differentiation, but it inhibited the differentiation of other $\mathrm{T}_{\mathrm{H}}$ cell subsets, by direct interaction with T-bet, GATA 3 and retinoic acid receptor-related orphan receptor- $\gamma \mathrm{t}(\mathrm{ROR} \gamma \mathrm{t})^{143-145}$. It is therefore possible that the previously reported BCL-6-mediated IL-10 suppression in $\mathrm{T}_{\mathrm{H}} 2$ cells $^{142}$ is a consequence of the inhibition of the $\mathrm{T}_{\mathrm{H}} 2$ cell differentiation pathways and therefore not due to a direct effect of BCL-6 on Il10 transcription. In support of this, no BCL- 6 consensus binding sites have as yet been found in the $I l 10$ promoter ${ }^{142}$.

The complexity of ILI0 regulation by different cells of the immune system, having both positive and negative feedback loops, shows the tight control that is essential to achieve a balance between an effective immune response and immunopathology. This complex regulation ranges from common to distinct pathways of IL-10 induction in different cell types.

\section{Mechanisms of post-transcriptional regulation}

Modulation of mRNA stability is an important component in the regulation of expression of several cytokines (reviewed in REF. 146) and most cytokine genes have a long 3' untranslated region (UTR), containing class II adenosine-uridine-rich elements (ARE) that target mRNAs for rapid degradation. Multiple copies of potential mRNA destabilizing motifs are found in the 3' UTR of Il10 $\mathrm{mRNA}^{147}$. Various factors can alter the stability of Il10 mRNA, including IL-10 itself, which triggers Il10 mRNA degradation ${ }^{148,149}$, and adenosine receptor activation, which acts by relieving the translational repressive effect of the Il10 3' UTR thereby increasing the mRNA half-life and the amount of IL-10 produced ${ }^{150}$.

More recently, Il10 mRNA has been identified as a tristetraprolin (TTP) target in a wide genome screen ${ }^{151}$. TTP is a RNA-binding molecule that can induce rapid degradation of mRNA following binding to AREs in 3' UTRs. Supporting this finding, macrophages from TTP-deficient mice showed a decrease in the rate of Il10 mRNA decay and an increase in IL-10 secretion ${ }^{151}$. Moreover, activation of $\mathrm{p} 38$ has been reported to stabilize the Il10 mRNA by inhibiting the action of TTP ${ }^{152}$. Interestingly, IL-10 induces TTP expression in a STAT3dependent manner, contributing to the establishment of an anti-inflammatory programme ${ }^{153}$.

Finally, a role for microRNAs in the regulation of IL-10 expression has been described ${ }^{134}$. A recent report shows that the human microRNA miR-106a, expressed in cells of both lymphoid and myeloid origin, binds the 3' UTR of the IL10 mRNA and induces its degradation ${ }^{154}$.

This level of post-transcriptional regulation of IL-10 expression might explain why, despite the existence of common pathways for IL-10 induction, different cells ultimately secrete different amounts of IL-10. Thus, in addition to genetic regulation, post-transcriptional regulation contributes to the fine tuning of IL-10 expression.

\section{Conclusion and outstanding questions}

Owing to the key role of IL-10 in the immune response and the link between defective IL-10 production and certain autoimmune and inflammatory diseases, an understanding of the molecular mechanisms that regulate the expression of this cytokine is crucial.

The fact that various cell types can express IL-10 makes the subject of IL10 regulation challenging. It also highlights the complexity of this regulation. Several early studies on the molecular regulation of IL-10 reported apparent differences. The fact that cell lines and different conditions were used in most of these studies has certainly been a contributing factor to these discrepancies. Indeed, recent studies using primary T cells, macrophages and DCs show more consistent results between laboratories with respect to the regulation of IL10 expression.

Several general conclusions from these studies can be made: first, many cells of the innate and adaptive immune response produce IL-10 regardless of the stimulus. Second, different stimuli, or the strength of the stimulus, give rise to different levels of IL-10 in the same cell type. Third, some of the molecular mechanisms for the regulation of IL-10 differ according to the cell 
type, although common mechanisms also exist. And fourth, IL-10 is induced in many situations together with pro-inflammatory cytokines, although the pathways that induce IL-10 expression may actually negatively regulate the expression of these pro-inflammatory cytokines.

Several outstanding questions and future challenges remain. Which cells are induced to produce IL-10 during an immune response to specific pathogens and gut flora, and which IL-10-producing cells are required to prevent host damage or to conversely inhibit immune responses, thereby contributing to chronic infection? What signalling pathways and transcription factors can specifically induce IL-10 in different immune cells independently of the induction of pro-inflammatory cytokines? What signalling pathways are required in different cells, and what is the hierarchy of transcription factor binding to IL10 regulatory elements? Is IL-10 production in vivo dictated by the environment and inflammatory stimuli, and what maintains the remodelling of the IL10 locus? For example, can $\mathrm{T}_{\mathrm{H}} 1$ cells detect signals and inflammatory molecules induced by microorganisms and their products in the microenvironment and turn on IL-10 production and thus reduce tissue damage? Many of these questions will be answered by comparing the kinetics and quantity of IL-10 expression and production in different immune cells stimulated with different stimuli and by elucidating the molecular signalling pathways leading to IL-10, by traditional biochemical methods, bioinformatics or high-throughput approaches, such as chromatin immunoprecipitation sequencing.

Outstanding questions might be answered by dissecting the mechanisms that regulate the expression of IL-10 in different cells, during different immune responses to microorganisms and in different anatomical locations (for example, comparing IL-10 expression in the lungs to the blood during M. tuberculosis infection ${ }^{73}$ ). An understanding of how IL-10 expression is regulated during such immune responses undoubtedly will be of use in developing therapeutic strategies to target IL-10 production in disease.
1. Hawrylowicz, C. M. \& O'Garra, A. Potential role of interleukin-10-secreting regulatory T cells in allergy and asthma. Nature Rev. Immunol. 5, 271-283 (2005).

2. O'Garra, A., Barrat, F. J., Castro, A. G., Vicari, A. \& Hawrylowicz, C. Strategies for use of IL-10 or its antagonists in human disease. Immunol. Rev. 223 114-131 (2008)

This review covers the most recent advances in the use of IL-10 in human disease, from immune-mediated diseases to cancer.

3. Moore, K. W., de Waal Malefyt, R., Coffman, R. L. \& O'Garra, A. Interleukin-10 and the interleukin-10 receptor. Annu. Rev. Immunol. 19, 683-765 (2001).

4. Kuhn, R., Lohler, J., Rennick, D., Rajewsky, K. \& Muller, W. Interleukin-10-deficient mice develop chronic enterocolitis. Cell 75, 263-274 (1993). This is the first report showing the important role of IL-10 in regulating the immune response and it suggests that the absence of IL-10 is associated with gut inflammation.

5. Sellon, R. K. et al. Resident enteric bacteria are necessary for development of spontaneous colitis and immune system activation in interleukin-10deficient mice. Infect. Immun. 66, 5224-5231 (1998).

6. Ejrnaes, M. et al. Resolution of a chronic viral infection after interleukin-10 receptor blockade. J. Exp. Med. 203, 2461-2472 (2006)

7. Brooks, D. G. et al. Interleukin-10 determines viral clearance or persistence in vivo. Nature Med. 12 1301-1309 (2006).

8. Gazzinelli, R. T. et al. In the absence of endogenous IL-10, mice acutely infected with Toxoplasma gondii succumb to a lethal immune response dependent on $\mathrm{CD} 4^{+} \mathrm{T}$ cells and accompanied by overproduction of IL-12, IFN- $\gamma$ and TNF- $\alpha$. J. Immunol. 157, 798-805 (1996).

9. Li, C., Corraliza, I. \& Langhorne, J. A defect in interleukin-10 leads to enhanced malarial disease in Plasmodium chabaudi chabaudi infection in mice. Infect. Immun. 67, 4435-4442 (1999).

10. O'Garra, A. $\&$ Vieira, P. T 1 cells control themselves by producing interleukin-10. Nature Rev. Immunol. 7, 425-428 (2007).

11. Trinchieri, G. Interleukin-10 production by effector T cells: Th 1 cells show self control. J. Exp. Med. 204, 239-243 (2007)

12. Fiorentino, D. F., Bond, M. W. \& Mosmann, T. R. Two types of mouse T helper cell. IV. Th2 clones secrete a factor that inhibits cytokine production by Th 1 clones. J. Exp. Med. 170, 2081-2095 (1989).

13. O'Garra, A. \& Vieira, P. Regulatory T cells and mechanisms of immune system control. Nature Med. 10, 801-805 (2004)

14 Roncarolo, M. G. et al. Interleukin-10-secreting type regulatory $\mathrm{T}$ cells in rodents and humans. Immunol. Rev. 212, 28-50 (2006).
15. Maynard, C. L. \& Weaver, C. T. Diversity in the contribution of interleukin-10 to T-cell-mediated immune regulation. Immunol. Rev. 226, 219-233 (2008).

16. Maloy, K. J. \& Powrie, F. Regulatory T cells in the control of immune pathology. Nature Immunol. 2, 816-822 (2001)

17. Hoffmann, K. F. Cheever, A. W. \& Wynn, T. A IL-10 and the dangers of immune polarization: excessive type 1 and type 2 cytokine responses induce distinct forms of lethal immunopathology in murine schistosomiasis. J. Immunol. 164, 6406-6416 (2000).

18. Grunig, G. et al. Interleukin-10 is a natural suppressor of cytokine production and inflammation in a murine model of allergic bronchopulmonary aspergillosis. J. Exp. Med. 185, 1089-1099 (1997).

19. Zuany-Amorim, C. et al. Interleukin-10 inhibits antigen-induced cellular recruitment into the airways of sensitized mice. J. Clin. Invest. 95, 2644-2651 (1995).

20. Murray, P. J. Understanding and exploiting the endogenous interleukin-10/STAT3-mediated antiinflammatory response. Curr. Opin. Pharmacol. 6. 379-386 (2006)

21. Barrat, F. J. et al. In vitro generation of interleukin 10-producing regulatory $\mathrm{CD} 4^{+} \mathrm{T}$ cells is induced by immunosuppressive drugs and inhibited by Thelper type 1 (Th1)- and Th2-inducing cytokines. J. Exp. Med. 195, 603-616 (2002)

22. Medzhitov, R. Recognition of microorganisms and activation of the immune response. Nature 449 , 819-826 (2007)

23 Fiorentino, D. F. Zlotnik, A., Mosmann, T. R. Howard, M. \& O'Garra, A. IL-10 inhibits cytokine production by activated macrophages. J. Immunol. 147, 3815-3822 (1991)

This study shows for the first time that IL-10 can block an immune response by suppressing cytokine production by mouse macrophages, suggesting that these cells are targets for IL-10 function.

24. de Waal Malefyt, R., Abrams, J., Bennett, B., Figdor, C. G. \& de Vries, J. E. Interleukin 10 (IL-10) inhibits cytokine synthesis by human monocytes: an autoregulatory role of IL-10 produced by monocytes. J. Exp. Med 174, 1209-1220 (1991).

This study shows for the first time that IL-10 can block an immune response by suppressing cytokine production by human monocytes, thereby positioning these cells as targets for IL-10 function.

25. Gerber, J. S. \& Mosser, D. M. Reversing lipopolysaccharide toxicity by ligating the macrophage Fc $\gamma$ receptors. J. Immunol. 166, 6861-6868 (2001)

26. Boonstra, A. et al. Macrophages and myeloid dendritic cells, but not plasmacytoid dendritic cells, produce IL-10 in response to MyD88- and TRIFdependent TLR signals, and TLR-independent signals. J. Immunol. 177, 7551-7558 (2006).
27 Chang, E. Y., Guo, B., Doyle, S. E. \& Cheng, G. Cutting edge: involvement of the type I IFN production and signaling pathway in lipopolysaccharide-induced IL-10 production. J. Immunol. 178, 6705-6709 (2007).

28. Edwards, A. D. et al. Microbial recognition via Toll-like receptor-dependent and -independent pathways determines the cytokine response of murine dendritic cell subsets to CD40 triggering. J. Immunol. 169 3652-3660 (2002).

29. Agrawal, S. et al. Cutting edge: different Toll-like receptor agonists instruct dendritic cells to induce distinct Th responses via differential modulation of extracellular signal-regulated kinase-mitogenactivated protein kinase and c-Fos. J. Immunol. 171, 4984-4989 (2003).

30. Dillon, S. et al. A Toll-like receptor 2 ligand stimulates Th2 responses in vivo, via induction of extracellular signal-regulated kinase mitogen-activated protein kinase and c-Fos in dendritic cells. J. Immunol. 172 , 4733-4743 (2004).

31. McGuirk, P., McCann, C. \& Mills, K. H. Pathogen specific $\mathrm{T}$ regulatory 1 cells induced in the respiratory tract by a bacterial molecule that stimulates interleukin 10 production by dendritic cells: a novel strategy for evasion of protective T helper type 1 responses by Bordetella pertussis. J. Exp. Med. 195 , 221-231 (2002)

32. Rogers, N. C et al. Syk-dependent cytokine induction by Dectin- 1 reveals a novel pattern recognition pathway for C type lectins. Immunity 22, 507-517 (2005).

33. Geijtenbeek, T. B. et al. Mycobacteria target DC-SIGN to suppress dendritic cell function. J. Exp. Med. 197 7-17 (2003).

34. Akbari, O., DeKruyff, R. H. \& Umetsu, D. T. Pulmonary dendritic cells producing IL-10 mediate tolerance induced by respiratory exposure to antigen. Nature Immunol. 2, 725-731 (2001)

35. Siewe, L. et al. Interleukin-10 derived from macrophages and/or neutrophils regulates the inflammatory response to LPS but not the response to CpG DNA. Eur. J. Immunol. 36, 3248-3255 (2006)

36. Zhang, X., Majlessi, L., Deriaud, E., Leclerc, C. \& Lo-Man, R. Coactivation of Syk kinase and MyD88 adaptor protein pathways by bacteria promotes regulatory properties of neutrophils. Immunity 31, 761-771 (2009)

37. Netea, M. G. et al. Toll-like receptor 2 suppresses immunity against Candida albicans through induction of IL-10 and regulatory T cells. J. Immunol. 172, 3712-3718 (2004).

38. Hu, X. et al. IFN- $\gamma$ suppresses IL-10 production and synergizes with TLR2 by regulating GSK3 and CREB/AP-1 proteins. Immunity 24, 563-574 (2006).

This study provides the first molecular basis for the negative feedback loops that regulate IL-10 expression. 
39. Jang, S., Uematsu, S., Akira, S. \& Salgame, P. IL-6 and IL-10 induction from dendritic cells in response to Mycobacterium tuberculosis is predominantly dependent on TLR2-mediated recognition. J. Immunol. 173, 3392-3397 (2004).

40. Sing, A. et al. Yersinia V-antigen exploits Toll-like receptor 2 and CD14 for interleukin 10-mediated immunosuppression. J. Exp. Med. 196, 1017-1024 (2002).

41. Moreira, L. O. et al. The TLR2-MyD88-NOD2RIPK2 signalling axis regulates a balanced proinflammatory and IL-10-mediated anti-inflammatory cytokine response to Gram-positive cell walls. Cell. Microbiol. 10, 2067-2077 (2008)

42. Hacker, H. et al. Specificity in Toll-like receptor signalling through distinct effector functions of TRAF3 and TRAF6. Nature 439, 204-207 (2006).

43. Akira, S. \& Takeda, K. Toll-like receptor signalling. Nature Rev. Immunol. 4, 499-511 (2004).

44. Symons, A., Beinke, S. \& Ley, S. C. MAP kinase kinase kinases and innate immunity. Trends Immunol. 27, 40-48 (2006)

45. Yi, A. K. et al. Role of mitogen-activated protein kinases in CpG DNA-mediated IL-10 and IL-12 production: central role of extracellular signal-regulated kinase in the negative feedback loop of the CpG DNA-mediated Th1 response. J. Immunol. 168, 4711-4720 (2002).

46. Agrawal, A., Dillon, S., Denning, T. L. \& Pulendran, B. ERK $1^{-1-}$ mice exhibit Th1 cell polarization and increased susceptibility to experimental autoimmune encephalomyelitis. J. Immunol. 176, 5788-5796 (2006).

47. Kaiser, F. et al. TPL-2 negatively regulates interferon- $\beta$ production in macrophages and myeloid dendritic cells. J. Exp. Med. 206, 1863-1871 (2009)

48. Beinke, S. \& Ley, S. C. Functions of NF-kB1 and NF-кB2 in immune cell biology. Biochem. J. 382 393-409 (2004)

49. Banerjee, A., Gugasyan, R., McMahon, M. $\Sigma$ Gerondakis, S. Diverse Toll-like receptors utilize Tpl2 to activate extracellular signal-regulated kinase (ERK) in hemopoietic cells. Proc. Natl Acad. Sci. USA 103, 3274-3279 (2006).

50. Kanters, E. et al. Inhibition of NF-кB activation in macrophages increases atherosclerosis in LDL receptor-deficient mice. J. Clin. Invest. 112 1176-1185 (2003)

51. Saraiva, M. et al. Identification of a macrophage specific chromatin signature in the IL-10 locus. J. Immunol. 175, 1041-1046 (2005)

52. Gringhuis, S. I. et al. C-type lectin DC-SIGN modulates Toll-like receptor signaling via Raf- 1 kinase-dependent acetylation of transcription factor NF-кB. Immunity 26, 605-616 (2007)

53. Gantner, B. N., Simmons, R. M., Canavera, S. J., Akira, S. \& Underhill, D. M. Collaborative induction of inflammatory responses by dectin-1 and Toll-like receptor 2. J. Exp. Med. 197, 1107-1117 (2003).

54. Slack, E. C. et al. Syk-dependent ERK activation regulates IL-2 and IL-10 production by DC stimulated with zymosan. Eur. J. Immunol. 37, 1600-1612 (2007).

55. Lucas, M. Zhang, X., Prasanna, V. \& Mosser, D. M. ERK activation following macrophage $F c \gamma R$ ligation leads to chromatin modifications at the IL-10 locus. J. Immunol. 175, 469-477 (2005).

56. Ma, W. et al. The p38 mitogen-activated kinase pathway regulates the human interleukin-10 promoter via the activation of $\mathrm{Sp} 1$ transcription factor in lipopolysaccharide-stimulated human macrophages. J. Biol. Chem. 276, 13664-13674 (2001).

57. Kim, C. et al. The kinase p38a serves cell type-specific inflammatory functions in skin injury and coordinates pro- and anti-inflammatory gene expression. Nature Immunol. 9, 1019-1027 (2008)

58. Park, J. M. et al. Signaling pathways and genes that inhibit pathogen-induced macrophage apoptosis CREB and NF-kB as key regulators. Immunity 23 319-329 (2005)

59 Jarnicki, A G et al. Attenuating regulatory T cell induction by TLR agonists through inhibition of p38 MAPK signaling in dendritic cells enhances their efficacy as vaccine adjuvants and cance immunotherapeutics. J. Immunol. 180, 3797-3806 (2008).

60. Foey, A. D. et al. Regulation of monocyte IL-10 synthesis by endogenous IL- 1 and TNF- $\alpha$ : role of the p38 and p42/44 mitogen-activated protein kinases. J. Immunol. 160, 920-928 (1998).

61. Chi, H. et al. Dynamic regulation of pro- and antiinflammatory cytokines by MAPK phosphatase 1 (MKP-1) in innate immune responses. Proc. Nat Acad. Sci. USA 103, 2274-2279 (2006).
62. Zhao, Q. et al. MAP kinase phosphatase 1 controls innate immune responses and suppresses endotoxic shock. J. Exp. Med. 203, 131-140 (2006).

63. Hammer, M. et al. Dual specificity phosphatase 1 (DUSP1) regulates a subset of LPS-induced genes and protects mice from lethal endotoxin shock. J. Exp. Med. 203, 15-20 (2006) References 61-63 identify the p38 regulator DUSP1 as a negative regulator of IL-10 expression, providing evidence that prolonged $\mathrm{p} 38$ activation leads to stronger IL-10 transcription.

64. Ananieva, O. et al. The kinases MSK1 and MSK2 act as negative regulators of Toll-like receptor signaling. Nature Immunol. 9, 1028-1036 (2008). This study shows that activation of MSK 1 and MSK 2 by $\mathrm{p} 38$ and ERK leads to enhanced IL-10 expression by macrophages and limits the production of pro-inflammatory cytokines.

65. Hammer, M. et al. Control of dual-specificity phosphatase- 1 expression in activated macrophage by IL-10. Eur. J. Immunol. 35, 2991-3001 (2005).

66. Lang, R., Patel, D., Morris, J. J., Rutschman, R. L. \& Murray, P. J. Shaping gene expression in activated and resting primary macrophages by IL-10. J. Immunol. 169, 2253-2263 (2002).

67. Staples, K. J. et al. IL-10 induces IL-10 in primary human monocyte-derived macrophages via the transcription factor Stat3. J. Immunol. 178, 4779-4785 (2007)

68. Moore, K. W. et al. Homology of cytokine synthesis inhibitory factor (IL-10) to the Epstein-Barr virus gene BCRFI. Science 248, 1230-1234 (1990).

69. Jankovic, D. et al. Conventional T-bet ${ }^{+}$Foxp3 Th1 cells are the major source of host-protective regulatory IL-10 during intracellular protozoan infection J. Exp Med 204, 273-283 (2007)

70. Anderson, C. F., Oukka, M., Kuchroo, V. J. \& Sacks, D CD4 ${ }^{+}$CD 25-Foxp3- Th 1 cells are the source of IL-10mediated immune suppression in chronic cutaneous leishmaniasis. J. Exp. Med. 204, 285-297 (2007). References 69 and 70 demonstrate the existence of IL-10-producing $T_{H} 1$ cells and their relevance during in vivo infections.

71. Gabrysova, L. et al. Negative feedback control of the autoimmune response through antigen-induced differentiation of IL-10-secreting Th1 cells. J. Exp. Med. 206, 1755-1767 (2009).

72. Saraiva, M. et al. Interleukin-10 production by Th cells requires interleukin-12-induced STAT4 transcription factor and ERK MAP kinase activation by high antigen dose. Immunity 31, 209-219 (2009).

This study provides the first molecular description of the pathways that regulate IL-10 expression by $T_{H} 1, T_{H} 2$ and $T_{H} 17$ cells, placing ERK, and possibly MAF, as components of a common pathway for IL-10 induction by $\mathrm{T}$ cells.

73. Gerosa, F. et al. CD4 ${ }^{+} \mathrm{T}$ cell clones producing both interferon- $\gamma$ and interleukin-10 predominate in bronchoalveolar lavages of active pulmonary tuberculosis patients. Clin. Immunol. 92, 224-234 (1999)

74. Meyaard, L., Hovenkamp, E., Otto, S. A. \& Miedema, F IL-12-induced IL-10 production by human T cells as a negative feedback for IL-12-induced immune responses. J. Immunol. 156, 2776-2782 (1996).

75. Yssel, H. et al. IL-10 is produced by subsets of human $\mathrm{CD}^{+} \mathrm{T}$ cell clones and peripheral blood T cells. J. Immunol. 149, 2378-2384 (1992).

76. Del Prete, G. et al. Human IL-10 is produced by both type 1 helper (Th1) and type 2 helper (Th2) T cell clones and inhibits their antigen-specific proliferation and cytokine production. J. Immunol. 150, 353-360 (1993)

77. McGeachy, M. J. et al. TGF- $\beta$ and IL- 6 drive the production of IL-17 and IL- 10 by T cells and restrain T -17 cell-mediated pathology. Nature Immunol. 8, 1390-1397 (2007)

78. Fitzgerald, D. C. et al. Suppression of autoimmune inflammation of the central nervous system by interleukin 10 secreted by interleukin 27-stimulated T cells. Nature Immunol. 8, 1372-1379 (2007)

79. Stumhofer, J. S. et al. Interleukins 27 and 6 induce STAT3-mediated T cell production of interleukin 10. Nature Immunol. 8, 1363-1371 (2007).

80. Veldhoen, M. et al. Transforming growth factor- $\beta$ 'reprograms' the differentiation of T helper 2 cells and promotes an interleukin 9-producing subset. Nature Immunol. 9, 1341-1346 (2008).

81. Rutz, S. et al. Notch regulates IL-10 production by T helper 1 cells. Proc. Natl Acad. Sci. USA 105, 3497-3502 (2008)

82. Zhu, J. et al. Conditional deletion of Gata3 shows its essential function in $\mathrm{T}_{1} 1-\mathrm{T}_{1} 2$ responses. Nature Immunol. 5, 1157-1165 (2004).
83. Shoemaker, J., Saraiva, M. \& O'Garra, A. GATA-3 directly remodels the $I L-10$ locus independently of IL-4 in CD4+ T cells. J. Immunol. 176, 3470-3479 (2006).

This study describes a new role for GATA3, showing that in addition to being the master regulator of $\mathrm{T}_{\mathrm{H}} 2$ cell differentiation, GATA 3 also controls the remodelling of the $I 110$ locus in $\mathrm{T}_{\mathrm{H}} 2$ cells.

84. Chang, H. D. et al. Expression of IL-10 in Th memory lymphocytes is conditional on IL-12 or IL-4, unless the IL-10 gene is imprinted by GATA-3. Eur. J. Immunol. 37, 807-817 (2007).

85. Xu, J. et al. c-Maf regulates IL-10 expression during Th1 7 polarization. J. Immunol. 182, 6226-6236 (2009).

This study provides evidence that MAF is a key transcription factor for IL-10 expression by $\mathrm{T}_{\mathrm{H}} 17$ cells and that MAF is not a $T_{H} 2$ cell-specific transcription factor.

86. Spolski, R., Kim, H. P., Zhu, W., Levy, D. E. \& Leonard, W. J. IL-21 mediates suppressive effects via its induction of IL-10. J. Immunol. 182, 2859-2867 (2009).

87. Batten, M. et al. Cutting edge: IL-27 is a potent inducer of IL-10 but not FoxP3 in murine T cells. J. Immunol. 180, 2752-2756 (2008)

88. Pot, C. et al. Cutting edge: IL-27 induces the transcription factor C-Maf, cytokine IL-21, and the costimulatory receptor ICOS that coordinately act together to promote differentiation of IL-10-producing Tr 1 cells. J. Immunol. 183, 797-801 (2009). In addition to reference 85 , this study supports the role of MAF as a key transcription factor for IL-10 expression in T cells, providing some insights on the molecular pathways that link MAF to IL-10 expression.

89. Kalliolias, G. D. \& Ivashkiv, L. B. IL-27 activates human monocytes via STAT1 and suppresses IL-10 production but the inflammatory functions of IL-27 are abrogated by TLRs and p38. J. Immunol. 180, 6325-6333 (2008).

90. Fuqua, C. F., Akomeah, R., Price, J. O. \& Adunyah, S. E. Involvement of ERK-1/2 in IL-21-induced cytokine production in leukemia cells and human monocytes. Cytokine 44, 101-107 (2008)

91. Owaki, T., Asakawa, M., Fukai, F., Mizuguchi, J. \& Yoshimoto, T. IL-27 induces Th1 differentiation via p38 MAPK/T-bet- and intercellular adhesion molecule-1/LFA-1/ERK1/2-dependent pathways. J. Immunol. 177, 7579-7587 (2006).

92. Maynard, C. L. et al. Contrasting roles for all-trans retinoic acid in TGF- $\beta$-mediated induction of Foxp3 and $/ 110$ genes in developing regulatory T cells. J. Exp. Med. 206, 343-357 (2009). This study provides molecular evidence for the regulation of IL-10 expression by $\mathrm{T}_{\mathrm{B}}$ cells.

93. Haringer, B., Lozza, L., Steckel, B. \& Geginat, J. Identification and characterization of IL-10/ IFN- $\gamma$-producing effector-like T cells with regulatory function in human blood. J. Exp. Med. 206, 1009-1017 (2009).

94. Rivino, L. et al. CCR6 is expressed on an IL-10-producing, auto-reactive memory T cell subset with context-dependent regulatory function. J. Exp. Med. (in the press).

95. Hori, S., Nomura, T. \& Sakaguchi, S. Control of regulatory $\mathrm{T}$ cell development by the transcription factor Foxp3. Science 299, 1057-1061 (2003).

96. Vieira, P. L. et al. IL-10-secreting regulatory T cells do not express Foxp3 but have comparable regulatory function to naturally occurring $\mathrm{CD} 4{ }^{+} \mathrm{CD} 25^{+}$regulatory T cells. J. Immunol. 172, 5986-5993 (2004).

97. Maynard, C. L. et al. Regulatory T cells expressing interleukin 10 develop from Foxp $3+$ and Foxp3precursor cells in the absence of interleukin 10. Nature Immunol. 8, 931-941 (2007).

98. Belkaid, Y. Regulatory T cells and infection: a dangerous necessity. Nature Rev. Immunol. 7 875-888 (2007).

99. Josefowicz, S. Z. \& Rudensky, A. Control of regulatory $T$ cell lineage commitment and maintenance. Immunity 30, 616-625 (2009).

100. Shevach, E. M. Mechanisms of foxp3+ T regulatory cell-mediated suppression. Immunity 30, 636-645 (2009).

101. Barthlott, T. et al. CD25+CD4+ T cells compete with naive $\mathrm{CD} 4^{+} \mathrm{T}$ cells for IL-2 and exploit it for the induction of IL-10 production. Int. Immunol. 17 279-288 (2005)

102. de la Rosa, M., Rutz, S., Dorninger, H. \& Scheffold, A Interleukin-2 is essential for $\mathrm{CD} 4{ }^{+} \mathrm{CD} 25^{+}$regulatory T cell function. Eur. J. Immunol. 34, 2480-2488 (2004). 
103. Sundstedt, A., O'Neill, E. J., Nicolson, K. S. \& Wraith, D. C. Role for IL-10 in suppression mediated by peptide-induced regulatory $\mathrm{T}$ cells in vivo. J. Immunol. 170, 1240-1248 (2003).

104. Mills, K. H. \& McGuirk, P. Antigen-specific regulatory $\mathrm{T}$ cells - their induction and role in infection. Semin. Immunol. 16, 107-117 (2004)

105. Akbari, O. et al. Antigen-specific regulatory T cells develop via the ICOS-ICOS-ligand pathway and inhibit allergen-induced airway hyperreactivity. Nature Med. 8, 1024-1032 (2002).

106. Ito, T. et al. Plasmacytoid dendritic cells prime IL-10producing T regulatory cells by inducible costimulator ligand. J. Exp. Med. 204, 105-115 (2007).

107. Witsch, E. J. et al. ICOS and CD28 reversely regulate IL-10 on re-activation of human effector T cells with mature dendritic cells. Eur. J. Immunol. 32 2680-2686 (2002)

108. Lohning, M. et al. Expression of ICOS in vivo defines $\mathrm{CD}_{4}^{+}$effector $\mathrm{T}$ cells with high inflammatory potential and a strong bias for secretion of interleukin 10 . J. Exp. Med. 197, 181-193 (2003).

109. Salgame, P. et al. Differing lymphokine profiles of functional subsets of human CD4 and CD8 T cell clones. Science 254, 279-282 (1991).

110. Tanchot, C. et al. Modifications of $\mathrm{CD}^{+} \mathrm{T}$ cell function during in vivo memory or tolerance induction. Immunity 8, 581-590 (1998)

111. Gilliet, M. $\&$ Liu, Y. J. Generation of human CD8 T regulatory cells by CD40 ligand-activated plasmacytoid dendritic cells. J. Exp. Med. 195 695-704 (2002)

112. O'Garra, A. et al. Ly-1 B (B-1) cells are the main source of B cell-derived interleukin 10. Eur. J. Immunol. 22 711-717 (1992).

113. Burdin, N., Rousset, F. \& Banchereau, J. B-cell-derived IL-10: production and function. Methods 11, 98-111 (1997).

114. Mauri, C., Gray, D., Mushtaq, N. \& Londei, M. Prevention of arthritis by interleukin 10-producing B cells. J. Exp. Med. 197, 489-501 (2003).

115. Fillatreau, S., Sweenie, C. H., McGeachy, M. J., Gray, D. $\&$ Anderton, S. M. B cells regulate autoimmunity by provision of IL-10. Nature Immunol. 3, 944-950 (2002).

116. Sun, C. M., Deriaud, E., Leclerc, C. \& Lo-Man, R. Upon TLR9 signaling, CD5+ B cells control the IL-12-dependent Th1-priming capacity of neonatal DCs. Immunity 22, 467-477 (2005)

117. Heine, G. et al. 1, 25-dihydroxyvitamin $D_{3}$ promotes IL-10 production in human B cells. Eur. J. Immunol. 38, 2210-2218 (2008)

118. Grimbaldeston, M. A., Nakae, S., Kalesnikoff, J., Tsai, M. \& Galli, S. J. Mast cell-derived interleukin 10 limits skin pathology in contact dermatitis and chronic irradiation with ultraviolet B. Nature Immunol. 8, 1095-1104 (2007).

119. Masuda, A., Yoshikai, Y., Aiba, K. \& Matsuguchi, T. Th2 cytokine production from mast cells is directly induced by lipopolysaccharide and distinctly regulated by $\mathrm{c}$-Jun $\mathrm{N}$-terminal kinase and $\mathrm{p} 38$ pathways. J. Immunol. 169, 3801-3810 (2002).

120 Brightbill, H. D. Plevy, S. E., Modlin, R. L. \& Smale, S. T. A prominent role for Sp1 during lipopolysaccharide-mediated induction of the IL-10 promoter in macrophages. J. Immunol. 164, 1940-1951 (2000)

121. Tone, M., Powell, M. J., Tone, Y., Thompson, S. A. \& Waldmann, H. IL-10 gene expression is controlled by the transcription factors Sp1 and Sp3. J. Immunol. 165, 286-291 (2000).

122. Brenner, S. et al. cAMP-induced interleukin-10 promoter activation depends on CCAAT/enhancer-binding protein expression and monocytic differentiation. J. Biol. Chem 278, 5597-5604 (2003).

123. Liu, Y. W., Tseng, H. P., Chen, L. C., Chen, B. K. \& Chang, W. C. Functional cooperation of simian virus 40 promoter factor 1 and CCAAT/enhancer-binding protein $\beta$ and $\delta$ in lipopolysaccharide-induced gene activation of IL-10 in mouse macrophages. J. Immunol. 171, 821-828 (2003).

124. Ziegler-Heitbrock, L. et al. IFN-a induces the human IL-10 gene by recruiting both IFN regulatory factor 1 and Stat3. J. Immunol. 171, 285-290 (2003).

125. Mori, N. \& Prager, D. Activation of the interleukin-10 gene in the human T lymphoma line HuT 78 . identification and characterization of NF-KB binding sites in the regulatory region of the interleukin-10 gene. Eur. J. Haematol. 59, 162-170 (1997).

126. Cao, S., Zhang, X., Edwards, J. P. \& Mosser, D. M NF-кB1 ( 550 ) homodimers differentially regulate pro- and anti-inflammatory cytokines in macrophages. J. Biol. Chem. 281, 26041-26050 (2006).
127. Chakrabarti, A et al. Protein kinase R-dependent regulation of interleukin-10 in response to doublestranded RNA. J. Biol. Chem. 283, 25132-25139 (2008).

128. Csoka, B. et al. A2A adenosine receptors and C/EBP are crucially required for $\mathrm{IL}-10$ production by macrophages exposed to Escherichia coli. Blood 110 , 2685-2695 (2007)

129. Chung, E. Y. et al. Interleukin-10 expression in macrophages during phagocytosis of apoptotic cells is mediated by homeodomain proteins $\mathrm{Pbx} 1$ and Prep-1. Immunity 27, 952-964 (2007).

130. Kitani, A. et al. Transforming growth factor (TGF)- $\beta 1$-producing regulatory T cells induce Smad mediated interleukin 10 secretion that facilitates coordinated immunoregulatory activity and amelioration of TGF- $\beta 1$-mediated fibrosis. J. Exp. Med. 198, 1179-1188 (2003).

131. Kim, J. I., Ho, I. C., Grusby, M. J. \& Glimcher, L. H. The transcription factor c-Maf controls the production of interleukin-4 but not other Th2 cytokines. Immunity 10, 745-751 (1999).

132. Cao, S., Liu, J., Song, L. \& Ma, X. The protooncogene c-Maf is an essential transcription factor for IL-10 gene expression in macrophages. J. Immunol. 174 3484-3492 (2005)

133. Wang, Z. Y. et al. Regulation of IL-10 gene expression in Th2 cells by Jun proteins. J. Immunol. 174 2098-2105 (2005)

134. Jones, E. A. \& Flavell, R. A. Distal enhancer elements transcribe intergenic RNA in the IL-10 family gene cluster. J. Immunol. 175, 7437-7446 (2005).

135. Im, S. H., Hueber, A., Monticelli, S., Kang, K. H. \& Rao, A. Chromatin-level regulation of the IL10 gene in T cells. J. Biol. Chem. 279, 46818-46825 (2004)

136. Grant, L. R. et al. Stat4-dependent, T-bet-independent regulation of IL-10 in NK cells. Genes Immun. 9, 316-327 (2008)

137. Grenningloh, R., Kang, B. Y. \& Ho, I. C. Ets-1, a functional cofactor of T-bet, is essential for Th inflammatory responses. J. Exp. Med. 201 615-626 (2005)

138. Sullivan, B. M. et al. Increased susceptibility of mice lacking T-bet to infection with Mycobacterium tuberculosis correlates with increased IL-10 and decreased IFN- $\gamma$ production. J. Immunol. 175 4593-4602 (2005)

139. Yee, C. S. et al. Enhanced production of IL-10 by dendritic cells deficient in CIITA. J. Immunol. 174 1222-1229 (2005)

140. VanDeusen, J. B. et al. STAT-1-mediated repression of monocyte interleukin-10 gene expression in vivo. Eur. J. Immunol. 36, 623-630 (2006).

141. Riemann, M., Endres, R., Liptay, S., Pfeffer, K. \& Schmid, R. M. The I $\mathrm{kB}$ protein $\mathrm{Bcl}-3$ negatively regulates transcription of the IL-10 gene in macrophages. J. Immunol. 175, 3560-3568 (2005)

142. Kusam, S., Toney, L. M., Sato, H. \& Dent, A. L. Inhibition of Th2 differentiation and GATA-3 expression by BCL-6. J. Immunol. 170, 2435-2441 (2003)

143. Nurieva, R. I. et al. Bcl6 mediates the development of T follicular helper cells. Science 325, 1001-1005 (2009)

144. Johnston, R. J. et al. Bcl6 and Blimp-1 are reciprocal and antagonistic regulators of $\mathrm{T}$ follicular helper cell differentiation. Science 325, 1006-1010 (2009).

145. Yu, D. et al. The transcriptional repressor $\mathrm{Bcl}-6$ directs $\mathrm{T}$ follicular helper cell lineage commitment. Immunity 31, 457-468 (2009).

146. Anderson, P. Post-transcriptional control of cytokine production. Nature Immunol. 9, 353-359 (2008)

147. Powell, M. J., Thompson, S. A., Tone, Y., Waldmann, H. $\&$ Tone, M. Posttranscriptional regulation of IL-10 gene expression through sequences in the 3'-untranslated region. J. Immunol. 165, 292-296 (2000)

148. Brown, C. Y., Lagnado, C. A., Vadas, M. A. \& Goodall, G. J. Differential regulation of the stability of cytokine mRNAs in lipopolysaccharide-activated blood monocytes in response to interleukin-10. J. Biol. Chem. 271, 20108-20112 (1996).

149. Kishore, R., Tebo, J. M., Kolosov, M. \& Hamilton, T. A. Cutting edge: clustered AU-rich elements are the target of IL-10-mediated mRNA destabilization in mouse macrophages. J. Immunol. 162, 2457-2461 (1999)

150. Nemeth, Z. H. et al. Adenosine augments IL-10 production by macrophages through an $\mathrm{A} 2 \mathrm{~B}$ receptormediated posttranscriptional mechanism. J. Immunol. 175, 8260-8270 (2005).
151. Stoecklin, G. et al. Genome-wide analysis identifies interleukin-10 mRNA as target of tristetraprolin. J. Biol. Chem. 283, 11689-11699 (2008)

152. Tudor, C. et al. The p38 MAPK pathway inhibits tristetraprolin-directed decay of interleukin-10 and pro-inflammatory mediator mRNAs in murine macrophages. FEBS Lett. 583, 1933-1938 (2009)

153. Schaljo, B. et al. Tristetraprolin is required for full anti-inflammatory response of murine macrophages to IL-10. J. Immunol. 183, 1197-1206 (2009).

154. Sharma, A. et al. Posttranscriptional regulation of interleukin-10 expression by hsa-miR-106a.

Proc. Natl Acad. Sci. USA 106, 5761-5766 (2009).

155. Izcue, A., Coombes, J. L. \& Powrie, F. Regulatory lymphocytes and intestinal inflammation. Annu. Rev. Immunol. 27, 313-338 (2009).

156. Spencer, S. D. et al. The orphan receptor CRF2-4 is an essential subunit of the interleukin 10 receptor. J. Exp. Med. 187, 571-578 (1998).

157. Roers, A. et al. T cell-specific inactivation of the interleukin 10 gene in mice results in enhanced $\mathrm{T}$ cell responses but normal innate responses to lipopolysaccharide or skin irritation. J. Exp. Med. 200, 1289-1297 (2004)

158. Groux, H. et al. A CD4+ T-cell subset inhibits antigen-specific T-cell responses and prevents colitis. Nature 389, 737-742 (1997)

159. Asseman, C., Read, S. \& Powrie, F. Colitogenic Th 1 cells are present in the antigen-experienced $\mathrm{T}$ cell pool in normal mice: control by $\mathrm{CD} 4{ }^{+}$regulatory T cells and IL-10. J. Immunol. 171, 971-978 (2003).

160. Van Montfrans, C. et al. Prevention of colitis by interleukin 10-transduced T lymphocytes in the SCID mice transfer model. Gastroenterology 123, 1865-1876 (2002).

161. Davidson, N. J. et al. T helper cell 1-type CD4+ $T$ cells, but not $B$ cells, mediate colitis in interleukin 10-deficient mice. J. Exp. Med 184, 241-251 (1996).

162. Franke, A. et al. Sequence variants in IL10, ARPC2 and multiple other loci contribute to ulcerative colitis susceptibility. Nature Genet. 40, 1319-1323 (2008).

163. Noguchi, E., Homma, Y., Kang, X., Netea, M. G. \& Ma, X. A Crohn's disease-associated NOD2 mutation suppresses transcription of human IL 10 by inhibiting activity of the nuclear ribonucleoprotein hnRNP-A1. Nature Immunol. 10, 471-479 (2009).

164. Coombes, J. L. et al. A functionally specialized population of mucosal CD103+ DCs induces Foxp3+ regulatory T cells via a TGF- $\beta$ and retinoic aciddependent mechanism. J. Exp. Med. 204 1757-1764 (2007).

165. Benson, M. J., Pino-Lagos, K., Rosemblatt, M. \& Noelle, R. J. All-trans retinoic acid mediates enhanced $T$ reg cell growth, differentiation, and gut homing in the face of high levels of co-stimulation. J. Exp. Med. 204, 1765-1774 (2007).

166. Sun, C. M. et al. Small intestine lamina propria dendritic cells promote de novo generation of Foxp3 T reg cells via retinoic acid. J. Exp. Med. 204, 1775-1785 (2007)

167. Zhang, X. Edwards, J. P. \& Mosser, D. M. Dynamic and transient remodeling of the macrophage IL-10 promoter during transcription. J. Immunol. 177, 1282-1288 (2006).

168. Villagra, A. et al. The histone deacetylase HDAC11 regulates the expression of interleukin 10 and immune tolerance. Nature Immunol. 10, 92-100 (2009).

\section{Acknowledgements}

We thank L. Gabrysova for critical reading of and commenting on this review and $\mathrm{A}$. Howes for careful proof reading.

\section{Competing interests statement}

The authors declare no competing financial interests.

DATABASES

UniProtKB: http://www.uniprot.org

CIITA | dectin 1 | DUSP1| ETS1 | IL-10 | MAF | MYD 88 | NOD2 STAT1 | STAT3 | STAT4 | SYK |T-bet |TRAF3 | TRIF |

FURTHER INFORMATION

Margarida Saraiva's homepage: http://www.icvs.uminho pt/icvs/domains/inf/cv/saraiva-m cv files/saraiva.m cv.htm Anne O’Garra's homepage: http://www.nimr.mrc.ac.uk/ immunoreg/ogarra/

ALL LINKS ARE ACTIVE IN THE ONLINE PDF 


\begin{abstract}
About the authors
Margarida Saraiva received her Ph.D. from the University of Cambridge, UK, in 2002. She subsequently carried out her postdoctoral research at the Medical Research Council National Institute for Medical Research (NIMR) on the molecular mechanisms of interleukin-10 (IL-10) gene regulation. In 2007 she joined the Life and Health Sciences Research Institute (ICVS) in Portugal. Her research programme focuses on the molecular regulation of macrophage and dendritic cell (DC) responses to Mycobacterium tuberculosis.
\end{abstract}

Anne O'Garra trained at the NIMR. She was then recruited to the DNAX Research Institute, California, USA. Her findings identified the roles of several key cytokines in the activation or downregulation of immune responses, and with this knowledge she is now pursuing therapeutic strategies for intervention in infectious diseases. Her most important contributions relate to the discovery of the immunosuppressive functions of IL-10, the production of IL-12 by essential antigen-presenting cells (APCs), DCs and macrophages, and the roles of IL-18 and IL-12 in inducing CD4 $4^{+} \mathrm{T}$ helper $1\left(\mathrm{~T}_{\mathrm{H}} 1\right)$ cell responses. Despite several offers of distinguished posts in the USA, she returned to the UK in 2001 to a permanent position as the Head of a new Division of Immunoregulation at the NIMR, to be an interface between the Divisions of Immunology and Infectious Diseases.

\title{
Online summary
}

- Interleukin-10 (IL-10) is not a cell type-specific cytokine, but instead it is broadly expressed by many immune cells.

- Several layers of regulation regulate IL-10 production, including changes in the chromatin structure, enhancement or silencing of IL10 transcription and post-transcriptional regulatory mechanisms.

- Many of the molecular events leading to IL10 expression are similar and common to various IL-10-producing immune cells, but cell type-specific signals also exist.

- Induction of IL-10 often occurs together with pro-inflammatory cytokines, although pathways that induce IL-10 may actually negatively regulate these pro-inflammatory cytokines.

- Understanding the specific molecular events that regulate the expression of IL-10 will be important for the design of new strategies of immune intervention.

TOC

\section{The regulation of IL-10 production by immune cells}

Margarida Saraiva and Anne O'Garra

The anti-inflammatory cytokine interleukin-10 (IL-10)

has a central role in limiting inflammatory responses

to protect against excessive tissue damage. Recent evidence suggests that many types of immune cell can produce IL-10, but how is its transcription regulated in these different cell types? 